\title{
Seasonal-to-Interannual Response of Southern Ocean Mixed Layer Depth to the Southern Annular Mode from a Global 1/10 Ocean Model
}

\author{
QIAN LI \\ Department of Meteorology and Atmospheric Science, The Pennsylvania State University, University Park, State College, \\ Pennsylvania, and Climate Change Research Centre and ARC Centre of Excellence for Climate System Science, \\ University of New South Wales, Sydney, New South Wales, Australia \\ SUKYOUNG LEE \\ Department of Meteorology and Atmospheric Science, The Pennsylvania State University, University Park, \\ State College, Pennsylvania \\ MATTHEW H. ENGLAND \\ Climate Change Research Centre and ARC Centre of Excellence for Climate Extremes, University of New \\ South Wales, Sydney, New South Wales, Australia \\ JULIE L. MCCLEAN \\ Scripps Institution of Oceanography, University of California, San Diego, La Jolla, California
}

(Manuscript received 26 February 2019, in final form 18 June 2019)

\begin{abstract}
The relationship between the southern annular mode (SAM) and Southern Ocean mixed layer depth (MLD) is investigated using a global $0.1^{\circ}$ resolution ocean model. The SAM index is defined as the principal component time series of the leading empirical orthogonal function of extratropical sea level pressure from September to December, when the zonally symmetric SAM feature is most prominent. Following positive phases of the SAM, anomalous deep mixed layers occur in the subsequent fall season, starting in May, particularly in the southeast Pacific. Composite analyses reveal that for positive SAM phases enhanced surface cooling caused by anomalously strong westerlies weakens the stratification of the water column, leading to deeper mixed layers during spring when the SAM signal is at its strongest. During the subsequent summer, the surface warms and the mixed layer shoals. However, beneath the warm surface layer, anomalously weak stratification persists throughout the summer and into fall. When the surface cools again during fall, the mixed layer readily deepens due to this weak interior stratification, a legacy from the previous springtime conditions. Therefore, the spring SAM-fall MLD relationship is interpreted here as a manifestation of reemergence of interior water mass anomalies. The opposite occurs after negative phases of the SAM, with anomalously shallow mixed layers resulting. Additional analyses reveal that for the MLD region in the southeast Pacific, the effects of salinity variations and Ekman heat advection are negligible, although Ekman heat transport may play an important role in other regions where mode water is formed, such as south of Australia and in the Indian Ocean.
\end{abstract}

\section{Introduction}

Atmospheric variability in the extratropical Southern Hemisphere ( $\mathrm{SH})$ is dominated by a nearly zonally symmetric mode known as the southern annular mode (SAM) (Gong and Wang 1999; Limpasuvan and Hartmann 1999; Thompson and Wallace 2000). The spatial pattern

Corresponding author: Qian Li, qian.li5@unsw.edu.au associated with the positive phase of the SAM is characterized by anomalously low pressure over the polar cap and anomalously high pressure over the midlatitudes, consistent with a poleward shift and intensification of the atmospheric westerly jet stream (Hartmann and Lo 1998). The SAM operates on a wide range of time scales ranging from high frequency, week-to-week interactions with synoptic eddies (Rashid and Simmonds 2005), through to low frequency at periods greater than 50 days 
(Kidson 1999; Lorenz and Hartmann 2001). Since the mid-1960s, an increasingly positive trend in the SAM index has also been reported (Thompson and Solomon 2002; Marshall 2003). The positive trend in the SAM over the past few decades has been attributed to both an increase in greenhouse gases and a decrease in stratospheric ozone concentrations (Kushner et al. 2001; Thompson and Solomon 2002; Gillett and Thompson 2003; Arblaster and Meehl 2006; Fyfe et al. 2007; Cai and Cowan 2007; Gillett et al. 2013), with the ozonerelated trend most pronounced during austral spring and summer. On interannual time scales, variations in the SAM have also been associated with El NiñoSouthern Oscillation (ENSO) variability (e.g., Seager et al. 2003; L'Heureux and Thompson 2006; Lim et al. 2013). Gong et al. (2010) showed that ENSO tends to modulate the background flow so that it is favorable for strong SAM phases to occur. Moreover, the SAM-related SH atmospheric anomalies account for changes not only in the zonal-mean circulation (Seager et al. 2003; Sen Gupta and England 2006) but also in the zonally varying circulation (L'Heureux and Thompson 2006).

The Southern Ocean response to the SAM has been the focus of much scientific research effort over the past two decades, in part because the SAM is the leading mode of atmospheric variability over this region, and also because the Southern Ocean plays a crucial role in regulating global climate by transporting and sequestering vast quantities of both heat and carbon (Sabine et al. 2004; Russell et al. 2006; Lenton and Matear 2007; Frölicher et al. 2015; Roemmich et al. 2015; Jones et al. 2016). The key doorway to this sequestration is the air-sea exchange of both heat and carbon, which is mediated by variations in mixed layer depth (MLD) (Sarmiento et al. 2004; Sallée et al. 2012) and the subsequent subduction of waters into the ocean interior. Some of the world's deepest mixed layers develop in the Southern Ocean, particularly on the equatorward flank of the Antarctic Circumpolar Current (ACC) (McCartney 1977). These deep mixed layers are associated with substantial heat (Dong et al. 2008) and carbon (Sarmiento et al. 2004; Sallée et al. 2012) uptake, and yet little is known about how these mixed layers vary over seasonal, interannual, and decadal time scales, including the variations in maximum MLD attained during winter and the mechanisms controlling this key climatic variable. The goal of this study is to examine variability in Southern Ocean MLD simulated in a nominal $0.1^{\circ}$ ocean general circulation model, and to investigate the role of the SAM in driving this variability via its impact on the sea surface buoyancy fluxes and the rate of ocean stratification.
Recent modeling studies suggest that ocean mixed layers are appreciably more accurate in high-resolution ocean model simulations than in simulations at coarser resolution where the dynamics are laminar (Lee et al. 2011; Schiller and Ridgway 2013; Li and Lee 2017). As shown in Fig. 1, Southern Ocean deep mixed layers occur in a $1 / 10^{\circ}$ resolution model simulation from early to late austral winter (June-October) in two key regions: 1) the Indian/southwest Pacific sector and 2) the southeast Pacific sector. These two deep MLD sectors are also seen in observed annual maximum MLDs derived from Argo floats. Although the model's MLDs are comparably deeper, their spatial distributions are in good overall agreement (Fig. 2). Several observationalbased studies have concluded that air-sea buoyancy loss and Ekman advection of buoyancy are the two dominant factors in forming deep mixed layers in the Southern Ocean north of the ACC (e.g., Rintoul and England 2002; Sallée et al. 2006; Dong et al. 2007, 2008; Downes et al. 2011; Holte et al. 2012; du Plessis et al. 2019). Air-sea buoyancy forcing has been argued to play the primary role in some studies (Sallée et al. 2010; Hogg 2010), while others argue that Ekman transport is the dominant mechanism, at least in terms of temperature and salinity $(T-S)$ variability in the winter mixed layer (e.g., Rintoul and England 2002). Alexander et al. (2000) presented evidence that the subsurface heat storage and re-entrainment into the mixed layer will in turn influence the surface air-sea heat exchange on interannual time scales.

The dynamic response of the ocean to the SAM has been investigated in many previous studies (Hall and Visbeck 2002; Screen et al. 2009; Treguier et al. 2010), including the MLD response (Sen Gupta and England 2006; Vivier et al. 2010; Sallée et al. 2010). In response to the SAM, the annual-mean MLD acts in phase to imprint a strong circumpolar signature onto sea surface temperature (SST) in the Southern Ocean from a coupled ocean-atmosphere-ice model (Sen Gupta and England 2006). The SAM-related MLD changes also have zonally asymmetric features in studies using a mixed layer model (Vivier et al. 2010) and observations (Sallée et al. 2010), especially in the aforementioned two deep MLD sectors where Subantarctic Mode Water formation occurs (Ayers and Strutton 2013). However, the temporal relationship between the SAM and MLD remains unclear. This potentially confounds the results, because the SAM atmospheric signal is strongest during austral summer, while MLD variations are largest during winter. Here, using a $0.1^{\circ}$ resolution ocean model, we will explore 1) the time evolution of MLD variability that ensues subsequent to anomalous austral summer SAM conditions, 2) the 

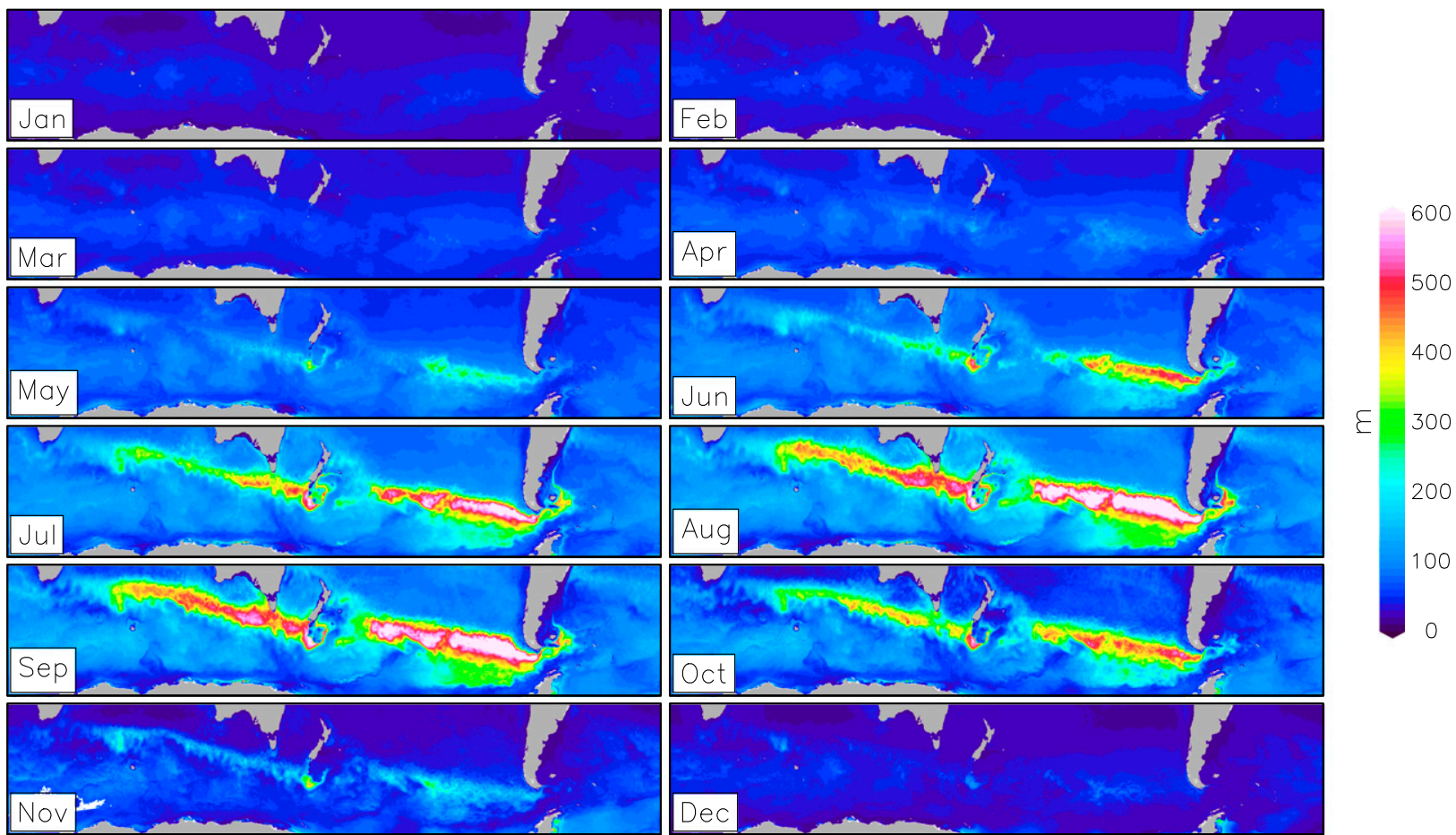

FIG. 1. Climatological monthly Southern Ocean MLD (color; m) from January to December in the $0.1^{\circ}$ POP model simulation.

contribution of sea surface buoyancy flux anomalies to this MLD variability, and 3) the rate of ocean stratification variability in the Southern Ocean. Moreover, mechanisms for a possible lead-lag relationship between the SAM and MLD will also be investigated. The remainder of this paper is organized as follows: in section 2 , we will describe the model simulation and methodology used in this study. The results will be presented in sections 3-6, and finally, conclusions and a summary will be presented in section 7 .

\section{Model description, data, and methodology}

\section{a. The global $1 / 10^{\circ}$ ocean model}

This study uses output from a nominal $0.1^{\circ}$ global ocean model simulation (Chen et al. 2014; Delman et al. 2015) carried out with the Los Alamos Parallel Ocean Program (POP) model (Smith et al. 1992) on the tripolar grid of Maltrud et al. (2010). In the Southern Ocean, the horizontal resolution ranges from $9 \mathrm{~km}$ at $36^{\circ} \mathrm{S}$ to $4 \mathrm{~km}$ at $69^{\circ} \mathrm{S}$, and hence it is eddy permitting in this region and only resolves the largest baroclinic mesoscale eddies. In the vertical, the POP model uses 42 levels with thickness ranging from $5 \mathrm{~m}$ at the surface to $250 \mathrm{~m}$ at $5500-\mathrm{m}$ depth. The POP simulation analyzed here was initialized from a $30-\mathrm{yr}$ spun-up state from an equivalent configuration that was forced with corrected Coordinated Ocean-Ice Reference Experiments version 2 (COREv2; Large and Yeager 2009) monthly climatological fluxes (Maltrud et al. 2010). The subsequent POP simulation was forced with corrected COREv2 interannually varying forcing (IAF) for 1990-2007; COREv2 6-hourly forcing fields were averaged to daily values and then interpolated to every time step. To transition from monthly mean forcing to IAF, four years of additional spinup were integrated over the period 1990-93 using the highfrequency forcing.

The Maltrud et al. simulation reaches a quasisteady state in terms of the upper ocean baroclinic velocity field (Maltrud et al. 2010); in contrast, substantial ongoing deep-ocean temperature and salinity adjustments continue to occur at this time scale. Drift below the MLD is however much weaker than the simulated surface variations, although there is a slight tendency toward warming in the deep ocean at the $\mathrm{SH}$ midlatitudes (not shown). The results described in this paper are based on daily output from the subsequent simulation for the period between 1994 and 2007. As such, the model used in this study is identical to that of Maltrud et al. (2010), except that our experiment was driven by forcing that is both highfrequency (6-hourly forcing averaged to daily values and then interpolated to every model time step) and 


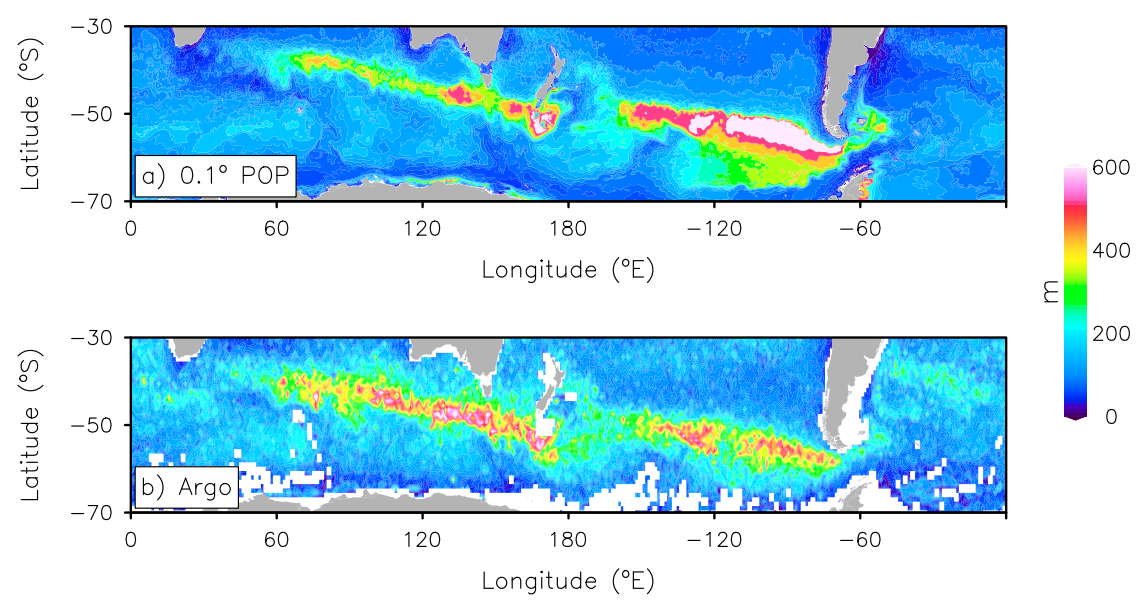

FIG. 2. Annual maximum Southern Ocean MLD (color; m) from the (a) $0.1^{\circ}$ POP model simulation and (b) Argo float data (Holte et al. 2017). The MLDs in both (a) and (b) are defined based on the density criterion $\left(\Delta \sigma=0.03 \mathrm{~kg} \mathrm{~m}^{-3}\right)$.

interannually varying rather than by a repeating monthly climatology.

We used the COREv2 dataset both to force the global ocean model and as a separate dataset for airsea interaction analysis. Sea level pressure (SLP), shortwave radiation, and precipitation fields are taken from the COREv2 forcing dataset (Large and Yeager 2009). Longwave radiation, evaporation, sensible heat and latent heat fluxes, and wind stress were postprocessed offline using bulk formulas in terms of the near-surface atmospheric and oceanic states. Latent heat fluxes were derived from evaporation. The preprocessed air-sea heat and freshwater flux output is only available over the period 1995-2007. The monthly model output and COREv2 forcing data analyzed in this study are detrended fields with the seasonal climatology removed. A spatial Gaussian boxcar $\left(20^{\circ} \times 20^{\circ}\right)$ smoothing filter [e.g., as in Williams et al. (2007)] was applied to the raw ocean model output that are used in the composite analyses to reveal the largerscale response. A Monte Carlo significance test was performed using 1000 samples for all anomaly fields presented.

\section{b. Springtime SAM index}

We analyze the monthly SLP field from COREv2 that was used to force the POP simulation to obtain the SAM pattern and index over the period of 1994-2007. Following Sen Gupta and England (2006), we perform an empirical orthogonal function (EOF) analysis on the SLP south of $20^{\circ} \mathrm{S}$, in order to exclude the impact of tropical variability. The leading SLP EOF patterns for each month are presented in Fig. 3. The spatial structure of the SAM is annular in austral spring, primarily during September-December (SOND), which is the time period in the Southern Hemisphere when stratosphere-troposphere coupling (Simpson et al. 2011) and nonstationary interannual variability external to potential feedbacks on SAM in the extratropics (Byrne et al. 2016) are most pronounced. Thus, we adopt the principal component (PC) time series of the leading EOF of annual SOND-mean SLP as our SAM index (Fig. 4). While this choice is somewhat arbitrary, we note that the resulting SAM index is not appreciably different from one defined using the SON-mean SLP (e.g., Fogt et al. 2012), and thus the index is not sensitive to the choice of the specific austral springtime period analyzed.

\section{c. Niño-3.4 index}

Variations in ENSO are indicated by the Niño-3.4 index computed from the POP simulation in this study. The daily Niño-3.4 index is obtained by averaging the daily SST anomalies over the Niño-3.4 region bounded by $170^{\circ}-120^{\circ} \mathrm{W}$ and $5^{\circ} \mathrm{N}-5^{\circ} \mathrm{S}$ (Fig. 4 ).

\section{d. Definition of the mixed layer depth}

Because temperature and salinity gradients tend to compensate in their effect on density (referred to commonly as density-compensating; Rudnick and Ferrari 1999) over the Southern Ocean, especially in regions of mode water formation (Rintoul and England 2002; Sallée et al. 2006; Dong et al. 2008), a buoyancy/densitybased MLD definition-rather than a temperaturebased definition-is applied. The POP-model simulated MLD is defined as the shallowest depth at which the buoyancy gradient relative to the surface equals the maximum buoyancy gradient within that water column [following the definition of Large et al. (1997)]. To test 

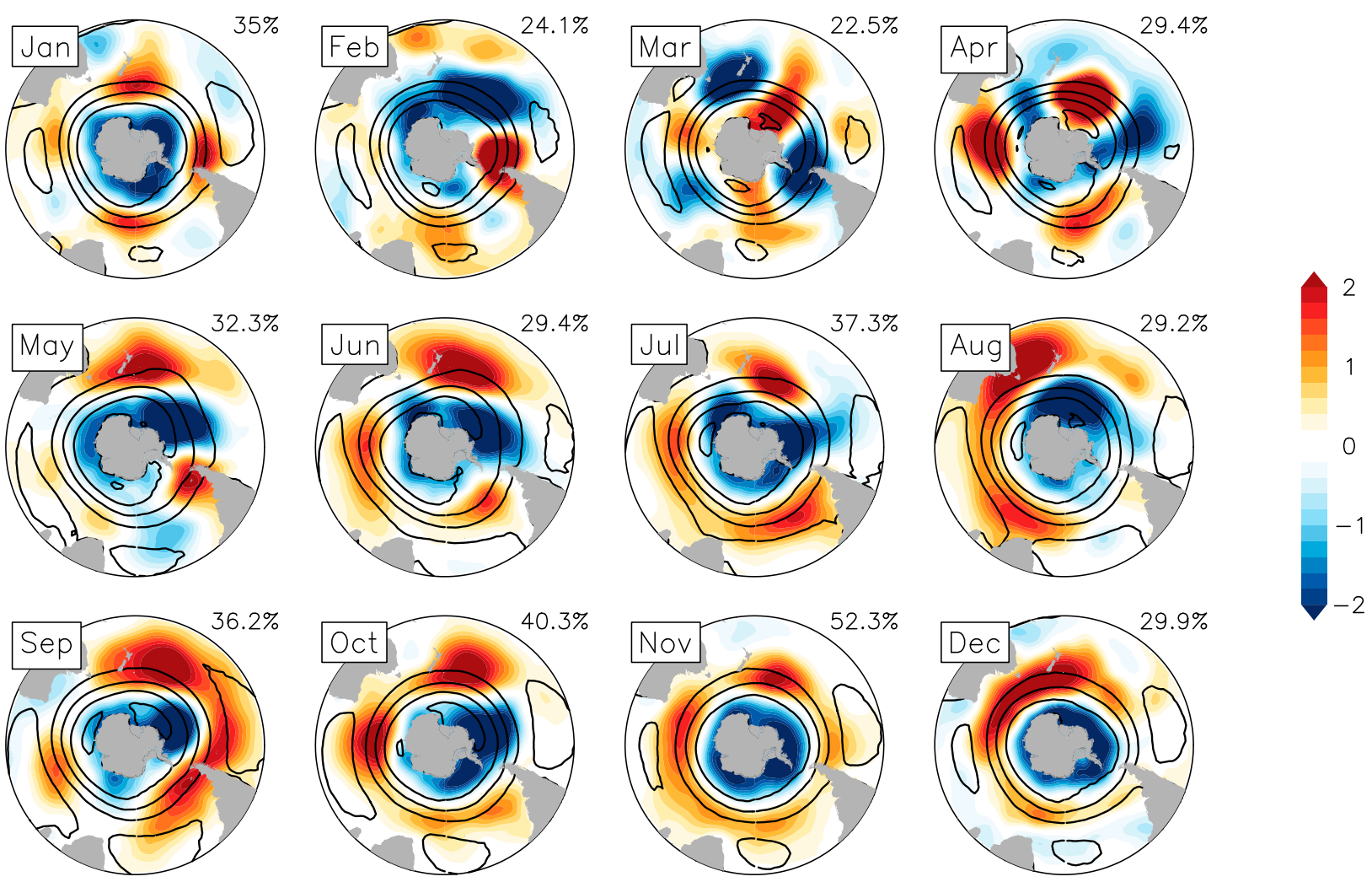

FIG. 3. Leading EOF patterns of extratropical SH sea level pressure (SLP; color shaded) for each month from January to December. The percentage of variance explained by each leading EOF is shown at the top right of each monthly panel. Contours indicate the climatological monthly SLP that exceeds $950 \mathrm{hPa}$, with a contour interval of $10 \mathrm{hPa}$. The SLP climatology used to produce this analysis is from the COREv2 dataset, which is used to force the $0.1^{\circ} \mathrm{POP}$ simulation.

the sensitivity of our main finding to this definition of MLD, we also consider another density-based threshold method (known as the finite difference definition), in which the base of the mixed layer is defined as the depth at which the potential density in the layer first exceeds a $0.03 \mathrm{~kg} \mathrm{~m}^{-3}$ threshold change relative to the surface density $\left(\Delta \sigma=0.03 \mathrm{~kg} \mathrm{~m}^{-3}\right)$ (e.g., de Boyer Montégut et al. 2004). The results presented in this study are robust to the choice of these two MLD definitions.

\section{The temporal evolution of the SAM}

The leading mode of atmospheric circulation variability is captured using the EOF analysis on the SLP

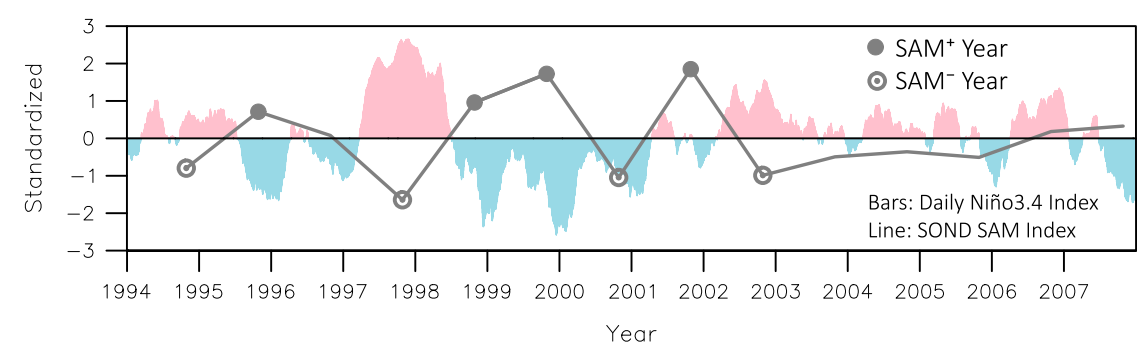

FIG. 4. The standardized daily Niño-3.4 index (pink/blue bars) and September-December (SOND) SAM index (solid line), defined as the leading EOF time series of annual SOND-mean SLP. The monthly SLP is taken from the COREv2 data, which is the synoptic forcing used in the $0.1^{\circ}$ POP model simulation. Solid dots and hollow dots indicate $\mathrm{SAM}^{+}$and $\mathrm{SAM}^{-}$years, respectively, defined as the standardized SAM index larger than \pm 0.7 . 
south of $20^{\circ} \mathrm{S}$. As shown in Fig. 3, the SAM signature is most apparent during austral springtime from September to December. During November in particular, in terms of a statistical correlation, the SAM accounts for $52.3 \%$ of the total variability in SLP, which is consistent with the SAM "active" season discussed previously in Thompson and Wallace (2000). In contrast, the leading EOF accounts for the smallest total variability during February-April, corresponding to the SAM "inactive" season. A transitional period occurs during the coldseason months (May-August) in between the so-called inactive and active SAM seasons. Therefore, the EOF calculation is further performed on the SOND-mean SLP. Using a standardized form of the PC time series of the leading EOF as a SOND SAM index (defined in section $2 b$ ) strong positive/negative SAM years are defined when the index exceeds \pm 0.7 . As a result, during our model simulation period there are four positive SAM years $\left(\mathrm{SAM}^{+}: 1995,1998,1999\right.$, and 2001) and four negative SAM years $\left(\mathrm{SAM}^{-}:\right.$1994, 1997, 2000, and 2002) identified (Fig. 4). The identification of extreme $\mathrm{SAM}^{+}$and $\mathrm{SAM}^{-}$years varies slightly across different reanalysis fields (e.g., ERA-Interim, JRA-55, COREv2). However, we choose to define these years based on the SAM index computed from COREv2, as this is the synoptic forcing applied in our POP simulation.

It is worth noting that these $\mathrm{SAM}^{+/-}$years appear to be associated in some way with ENSO. Previous studies (e.g., Gong et al. 2010) show that $\mathrm{SAM}^{+/-}$years are skewed toward particular La Niña/El Niño events linked to strong/weak anticyclonic atmospheric wave breaking on the equatorward side of the SH midlatitude eddydriven jet. The intensity of this ENSO-induced atmospheric wave breaking varies over daily time scales, hence in order to evaluate if this relationship holds during our analysis period, we consider the variations in ENSO using the daily Niño-3.4 index (defined in section 2c). As presented in Fig. 4, during most of our analysis period, the aforementioned SAM and ENSO relationship holds with the exception of year 2000. In contrast, because we focus on the Southern Ocean response to the SAM on the seasonal-to-interannual time scale, we adopt an annual austral spring index for the SAM.

We next examine average atmospheric and oceanic composite anomalies during two subsets of the simulated 1994-2007 record, corresponding to positive and negative SAM years. Figure 5 shows the composite SLP anomalies for the $\mathrm{SAM}^{+}$(left panel) and $\mathrm{SAM}^{-}$(right panel) years. During the springtime (e.g., September and November), consistent with the EOF analysis, the $\mathrm{SAM}^{+}$-composite SLP anomalies are characterized by an annular pattern with an anomalous low over the pole surrounded by an anomalous high between $40^{\circ}$ and $60^{\circ} \mathrm{S}$
(Figs. 5a,b). From the subsequent March to July, however, the SLP anomalies evolve toward a wavelike structure (Figs. 5d-f), which is reminiscent of the SLP pattern associated with ENSO (e.g., Cai and Baines 2001; Venegas 2003; Purich et al. 2016). The SAM ${ }^{-}$-composite anomalous SLP shows similar structure but with opposite sign (Figs. 5h,i,k,m).

\section{Southern Ocean MLD variations associated with the SAM}

The MLD anomalies in response to the $\mathrm{SAM}^{+}$(left panel) and $\mathrm{SAM}^{-}$(right panel) are shown in Fig. 6. In the SAM-peak springtime (i.e., September and November), MLD anomalies exhibit a slightly significant circumpolar feature with an increase (decrease) to the south and a decrease (increase) to the north, with the strongest signal over the southeast Pacific for the $\mathrm{SAM}^{+}$ (Fig. 6b) $\left[\mathrm{SAM}^{-}\right.$(Fig. 6i)] composites. Even during the following warm season (e.g., January and March) when actual MLDs are very shallow (Fig. 1), the MLD anomalies over the southeast Pacific continue to persist (Figs. 6c,d,j,k). In May, this persistent anomaly reaches its local peak found within the region indicated by $\pm 30 \mathrm{~m}$ (Figs. 6e,1). Its maximum absolute value is $\sim 120 \mathrm{~m}$. This southeast Pacific region may play an important role in the SAM-related air-sea exchange of heat and carbon, because it is the key location that is closely linked to Subantarctic Mode Water (SAMW) formation (McCartney 1977; Holte and Talley 2009; Sloyan et al. 2010; Cerovečki et al. 2013; Jones et al. 2016). During the subsequent cold season (i.e., JulySeptember), when the southeast Pacific MLD anomalies weaken, these anomalies evolve toward a more localized pattern (Figs. 6f,g,m,n). This zonally asymmetric MLD associated with the SAM was also discussed in Sallee et al. (2010). Our results further reveal a time-lag relationship wherein the annular feature of the SAM is most prominent during springtime, whereas the MLD anomalies, with their zonally asymmetric pattern, emerge several months later. Therefore, we investigate the SAM-MLD relationship on seasonal-to-interannual time scales in the rest of the paper. In particular, we will primarily focus on the SAM-related MLD variations in the southeast Pacific sector.

The ocean MLD development is closely tied to the distribution of ocean water-mass properties within the mixed layer. To explore key processes in the MLD development, we first investigate the mixed layer potential density anomalies in response to the $\mathrm{SAM}^{+}$(left panel) and $\mathrm{SAM}^{-}$(right panel), as shown in Fig. 7. The SAM ${ }^{+}$ and $\mathrm{SAM}^{-}$composites share similar spatial patterns, only of opposite sign. For the $\mathrm{SAM}^{+}$, during the warm 

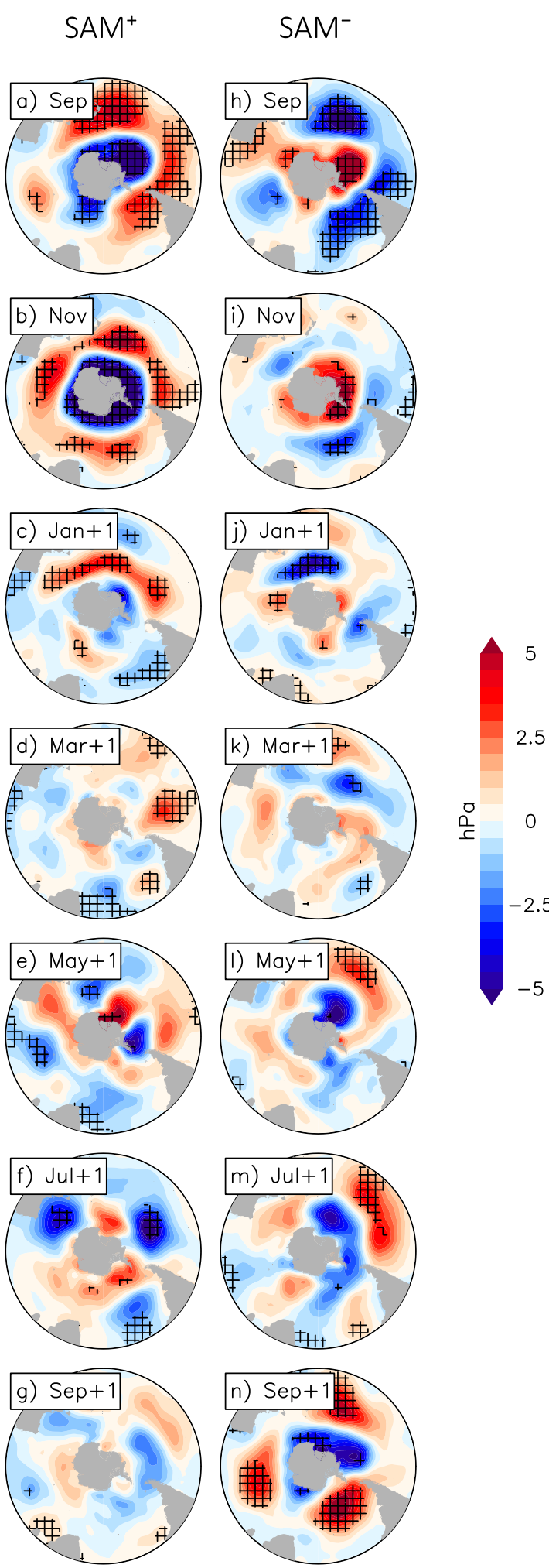

FIG. 5. Composite sea level pressure (SLP) anomalies (color; $\mathrm{hPa}$ ) south of $20^{\circ} \mathrm{S}$ for the (a)-(g) SAM ${ }^{+}$and (h)-(n) $\mathrm{SAM}^{-}$years from September of the initial $\mathrm{SAM}^{+/-}$anomaly to the following September. Stippling denotes regions where the significance level season (November, January, and March), density anomalies show an annular pattern, with an increase to the south and a decrease to the north (Figs. 7b-d). The annular feature appears about one or two months later (Figs. 5a,b), with greatest density anomalies occurring in the key southeast Pacific sector from November to the next May, with its maximum in January (Figs. 7b-e). This increase in density is consistent with the MLD variations in the southeast Pacific sector.

Mixed layer density depends on both potential temperature and salinity; we therefore examine both the potential temperature anomalies and salinity anomalies in response to the SAM. As shown in Fig. 8, for both the $\mathrm{SAM}^{+}$(left panel) and $\mathrm{SAM}^{-}$(right panel), mixed layer potential temperature anomalies show similarity with the potential density (Fig. 7) and salinity (not shown) anomalies. In response to the $\mathrm{SAM}^{+}$, during the month of January, there is a significant annular pattern with cooling to the south and warming to the north (Figs. 8b-d). This annular feature is consistent with the SAM regression analysis of Sen Gupta and England (2006), although their calculation was for the SST anomalies. They found that the largest response of mixed layer thermal capacity to the SAM lags the atmospheric response by $\sim 1$ month. They also suggested that air-sea heat fluxes were the dominant driver of SST anomalies related to the SAM, with an additional contribution from meridional Ekman fluxes. In contrast to the warm season, much less zonal symmetry appears in the $\mathrm{SAM}^{+}$composite potential temperature anomalies from May to September, with anomalous cooling in the southeast Pacific and warming in the Indian/southwest Pacific and southern Atlantic Ocean (Figs. 8e-g).

The relative contributions of both potential temperature and salinity anomalies are evaluated using a linear equation of state, expressed as

$$
\left.\Delta \sigma_{m}\right|_{\text {Est }}=\underbrace{-\alpha_{\theta} \sigma_{\text {ref }} \Delta \theta_{m}}_{\text {contribution of potential temperature }}+\underbrace{\beta_{S} \sigma_{\text {ref }} \Delta S_{m}}_{\text {contribution of salinity }},
$$

where $\sigma_{\text {ref }}=1000 \mathrm{~kg} \mathrm{~m}^{-3}$ is a reference potential density, $\alpha_{\theta}=1.2 \times 10^{-4} \mathrm{~K}^{-1}$ is the thermal expansion coefficient, and $\beta_{S}=7.8 \times 10^{-4} \mathrm{psu}^{-1}$ is the haline contraction coefficient. The estimated potential density anomalies $\left(\left.\Delta \sigma_{m}\right|_{\text {Est }}\right)$ calculated using this linear equation of state are nearly identical to those generated by the POP model using the McDougall et al. (2003) full

of the SLP anomalies is $>90 \%$ based on a Monte Carlo test from 1000 samples. The " +1 " indicates months occurring during the year following the anomalous $\mathrm{SAM}^{+/-}$austral spring. 

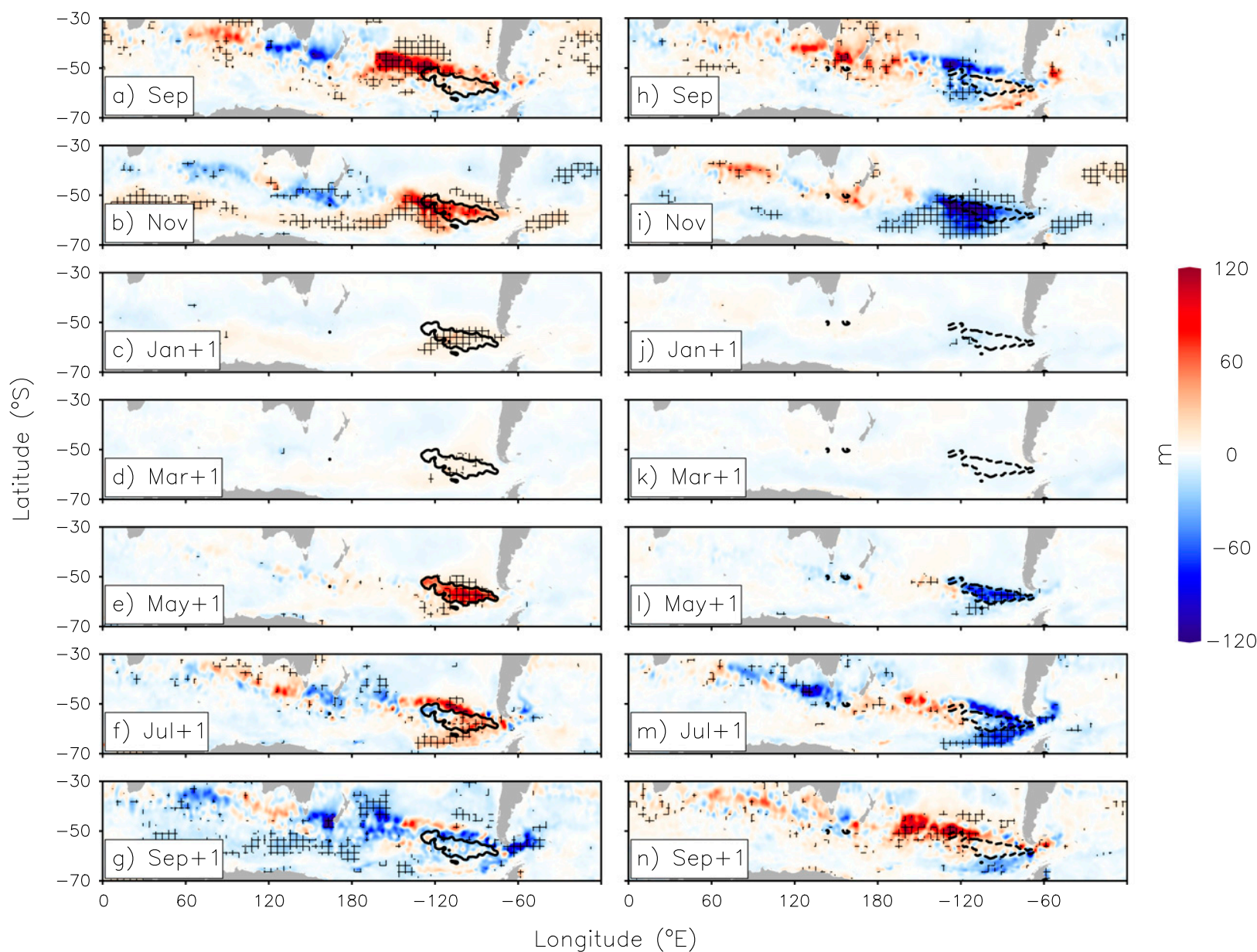

FIG. 6. Composite MLD anomalies (color; $m$ ) in the Southern Ocean for the (a)-(g) SAM ${ }^{+}$and (h)-(n) SAM ${ }^{-}$years from September of the initial $\mathrm{SAM}^{+/-}$anomaly to the following September. Stippling denotes regions where the significance level of the MLD anomalies is $>90 \%$ based on a Monte Carlo test from 1000 samples. Black solid (dashed) lines indicate the May MLD anomalies at $+30 \mathrm{~m}(-30 \mathrm{~m})$. The key sector of MLD development in the southeast Pacific Ocean. The " +1 " indicates months occurring during the year following the anomalous $\mathrm{SAM}^{+/-}$austral spring.

nonlinear equation of state, which is not surprising given the relatively small anomalies in mixed layer temperature and salinity considered here. The results (not shown) indicate that the potential density variations are mostly attributable to potential temperature anomalies, especially in the warm season. The time lead-lag relationship between the anomalous potential temperature (potential density) and MLDs suggests that the SAM-related tendency of potential temperature also plays an important role in MLD variations.

\section{Air-sea and Ekman fluxes associated with the SAM}

Having identified that the MLD variability is predominantly controlled by the mixed layer potential temperature anomalies, we now examine if the atmospheric forcing associated with the SAM can account for those potential temperature anomalies. The atmosphere can drive temperature anomalies directly via air-sea fluxes of heat and also indirectly via wind-driven circulation (e.g., Ekman transport). Both the surface heat fluxes and mixed layer Ekman advection associated with the SAM will be diagnosed in this section.

Variations in the net air-sea heat flux $\Delta Q_{\text {net }}$ give rise to a change in mixed layer potential temperature tendency, which can be calculated as follows:

$$
\left.\frac{\partial \Delta \theta_{m}}{\partial t}\right|_{\text {air-sea }}=-\frac{\Delta Q_{\text {net }}}{\sigma_{\text {ref }} c_{w} h_{m}}
$$

where $\theta_{m}$ is mixed layer potential temperature, $\sigma_{\text {ref }}=$ $1027 \mathrm{~kg} \mathrm{~m}^{-3}$ is a reference density, $c_{w}=4.18 \times$ $10^{3} \mathrm{~J} \mathrm{~kg}^{-1} \mathrm{~K}^{-1}$ is the heat capacity of seawater, $h_{m}$ is the depth of the MLD, and $Q_{\text {net }}$ from the atmosphere to the ocean is defined as positive. Penetration of downward 


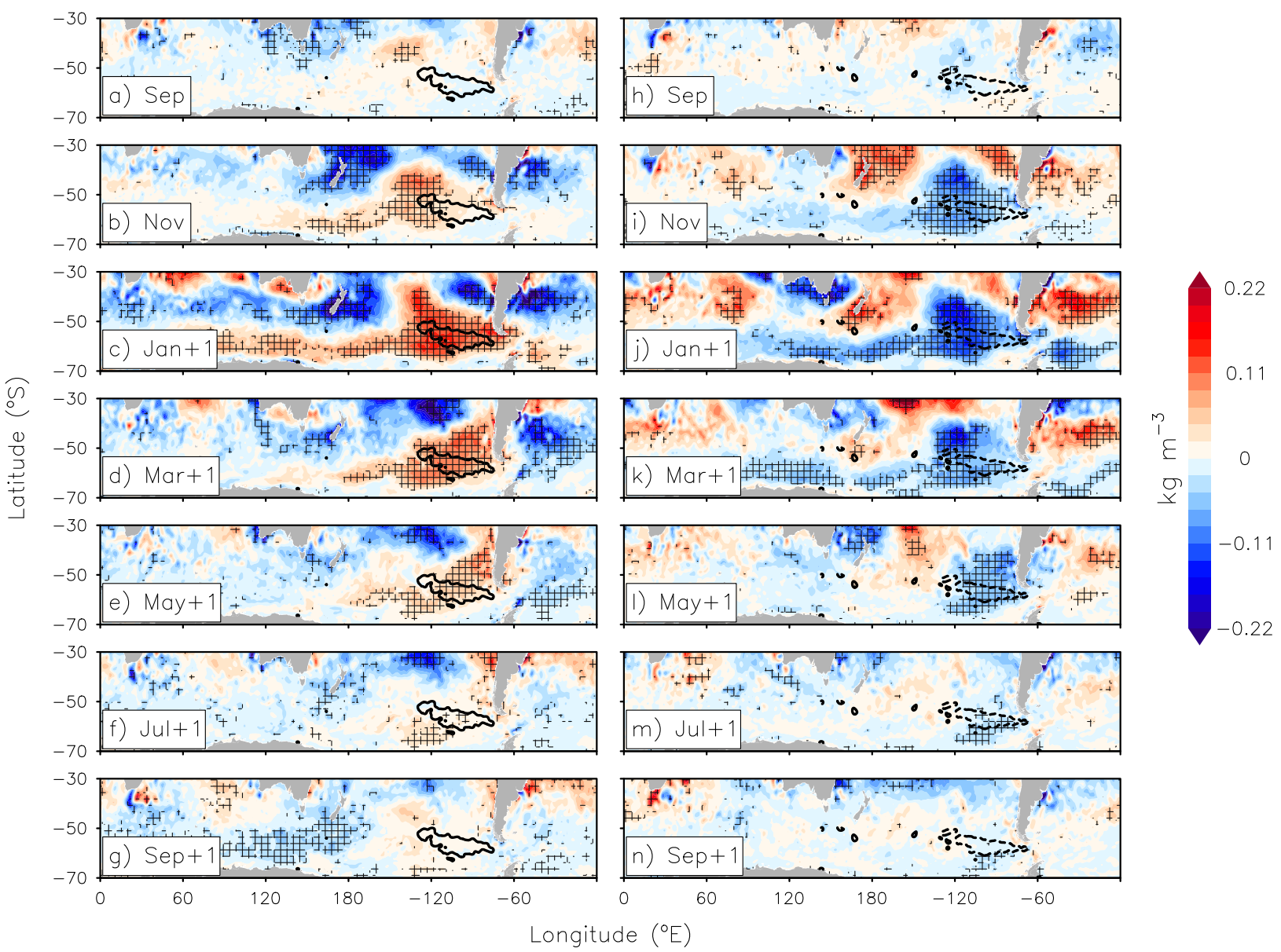

FIG. 7. Composite mixed layer potential density anomalies (color; $\mathrm{kg} \mathrm{m}^{-3}$ ) in the Southern Ocean for the (a)-(g) SAM ${ }^{+}$and (h)-(n) $\mathrm{SAM}^{-}$years from September of the initial $\mathrm{SAM}^{+/-}$anomaly to the following September. Stippling denotes regions where the significance level of the mixed layer potential density anomalies is $>90 \%$ based on a Monte Carlo test from 1000 samples. The black line is the same as that shown in Fig. 6. The " +1 " indicates months occurring during the year following the anomalous SAM ${ }^{+/-}$austral spring.

shortwave radiation below the mixed layer is found to be relatively small and is thus neglected here. Figure 9 presents the springtime response of the associated mixed layer potential temperature tendency term $\left[\left.\left(\partial \Delta \theta_{m} / \partial t\right)\right|_{\text {air-sea }}\right]$ for both the $\mathrm{SAM}^{+}$(left panel) and $\mathrm{SAM}^{-}$(right panel) composites. The significant annular pattern with cooling (warming) to the south and warming (cooling) to the north appears in November for the $\mathrm{SAM}^{+}\left(\mathrm{SAM}^{-}\right)$, with the greatest signal in the key southeast Pacific sector, as shown in Fig. 9b (Fig. 9e).

A similar calculation can be made of the change in mixed layer potential temperature attributed to variations in Ekman heat transport, expressed as

$$
\left.\frac{\partial \Delta \theta_{m}}{\partial t}\right|_{\text {Ekman }}=-u_{E} \frac{\partial \theta_{m}}{\partial x}-v_{E} \frac{\partial \theta_{m}}{\partial y}
$$

where $u_{E}=\tau_{y} /\left(\rho_{\text {ref }} f h_{m}\right)$ and $v_{E}=-\tau_{x} /\left(\rho_{\text {ref }} f h_{m}\right)$ are the horizontal and meridional components of the Ekman velocity, respectively. Figure 10 presents the springtime response of $\left.\left(\partial \Delta \theta_{m} / \partial t\right)\right|_{\text {Ekman }}$ term to the $\mathrm{SAM}^{+}$(left panel) and $\mathrm{SAM}^{-}$(right panel). Ekman heat transport drives much of the Southern Ocean mixed layer potential temperature tendency with an annular feature, which is consistent with previous studies (e.g., Rintoul and England 2002; Sen Gupta and England 2006; Dong et al. 2008; Downes et al. 2011). However, little signal in Ekman heat transport is seen in the southeast Pacific sector where SAM-driven variability is large (Figs. 10b,c,e,f).

The variations of net air-sea heat flux can be further decomposed into four terms:

$$
\Delta Q_{\text {net }}=\underbrace{\underbrace{\Delta Q_{\mathrm{SW}}}_{\text {hhortwave }}+\underbrace{\Delta Q_{\mathrm{LW}}}_{\text {longwave }}}_{\text {radiative }}+\underbrace{\underbrace{\Delta Q_{S}}_{\text {sensible flux }}+\underbrace{\Delta Q_{L}}_{\text {latent flux }}}_{\text {turbulent }},
$$

where $Q_{\mathrm{SW}}$ and $Q_{\mathrm{LW}}$ are the shortwave and longwave heat fluxes respectively, $Q_{S}$ and $Q_{L}$ are the sensible and 


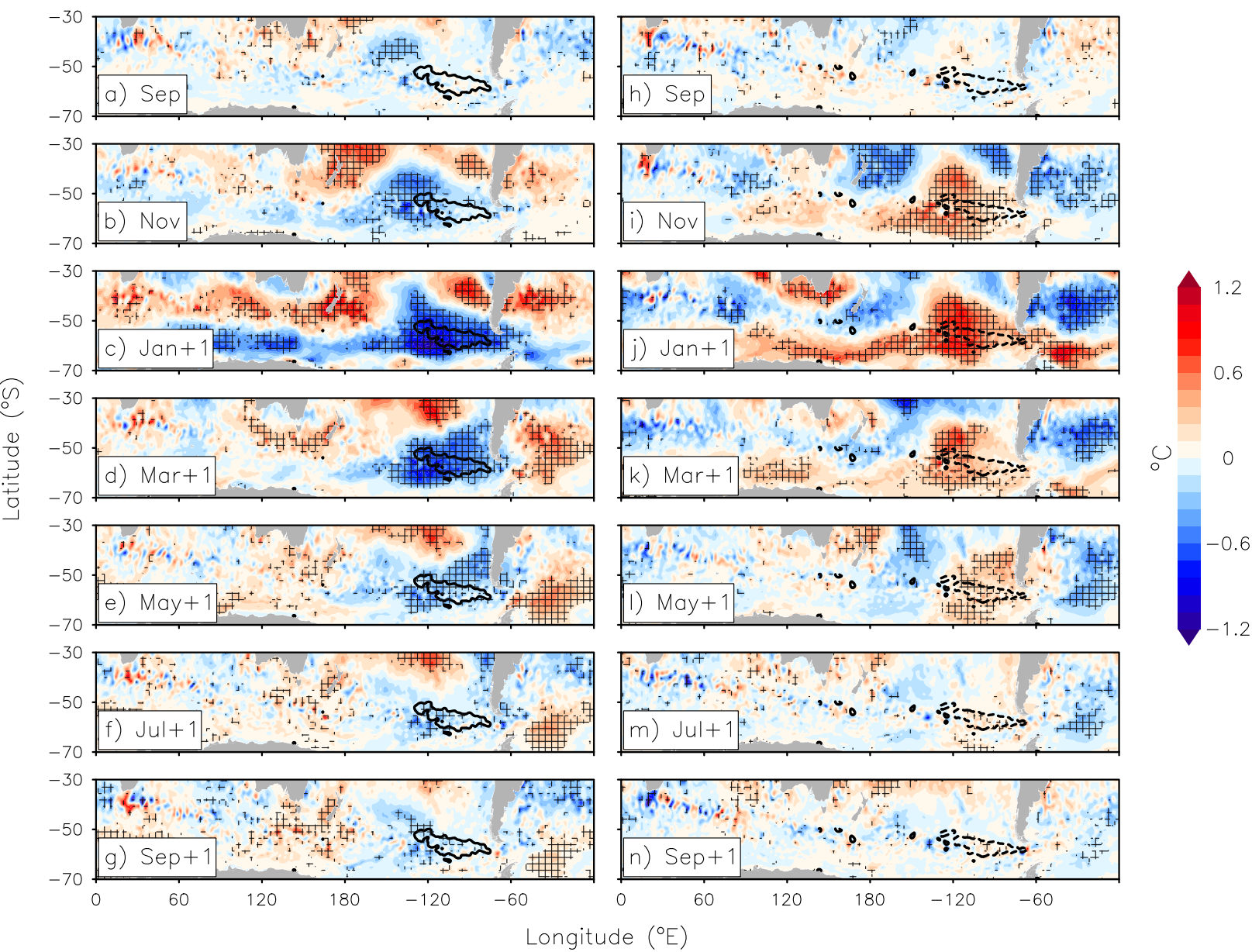

FIG. 8. As in Fig. 7, but for the mixed layer potential temperature anomalies (color; ${ }^{\circ} \mathrm{C}$ ).

latent heat fluxes respectively, and all air-sea heat fluxes from the atmosphere to the ocean are defined as positive. We computed each of the four terms on the right-hand side of (1), in which the radiative heat fluxes $\left(\Delta Q_{\text {sw }}\right.$ and $\left.\Delta Q_{\mathrm{LW}}\right)$ are taken from the COREv2 forcing data and the turbulent heat fluxes $\left(\Delta Q_{S}\right.$ and $\left.\Delta Q_{L}\right)$ are derived from the model output. The results indicate that the latent heat flux is the major contributor to net air-sea flux anomalies, largely compensated by total radiative heat flux anomalies. Because the near sea surface wind is an important factor in the ocean latent heat release, the 10-m zonal wind speed anomalies obtained from the COREv2 forcing data are further analyzed in relation to latent heat flux anomalies. During the peak $\mathrm{SAM}^{+}\left(\mathrm{SAM}^{-}\right)$period, westerly winds increase (decrease) in the southeast Pacific sector (Figs. 11a-d), while latent heat loss cools (warms) in the same region (Figs. 11e-h). In November, the latent heat flux anomalies show a significant annular pattern with the greatest variations over the southeast Pacific. We conclude that the SAM-related zonal winds are an important contributor to the latent heat fluxes and net air-sea heat flux in the southeast Pacific sector.

\section{Southeast Pacific variations associated with the SAM}

\section{a. Ocean mixed layer variation}

Given that the largest MLD anomaly develops in the southeast Pacific sector, we now analyze the variations in density and stratification averaged within that sector. Figure 12 shows the time series of MLD and potential density anomalies for $\mathrm{SAM}^{+}$(Fig. 12a) and $\mathrm{SAM}^{-}$ (Fig. 12e) composites. Also shown are the time series of potential temperature and salinity contribution to the potential density anomalies. The time series of the corresponding tendencies of all these variations are presented in Figs. 12b and 12f. As discussed in section 2c, the variation of potential density is predominantly caused by potential temperature, and the contribution 
$\mathrm{SAM}^{+}$
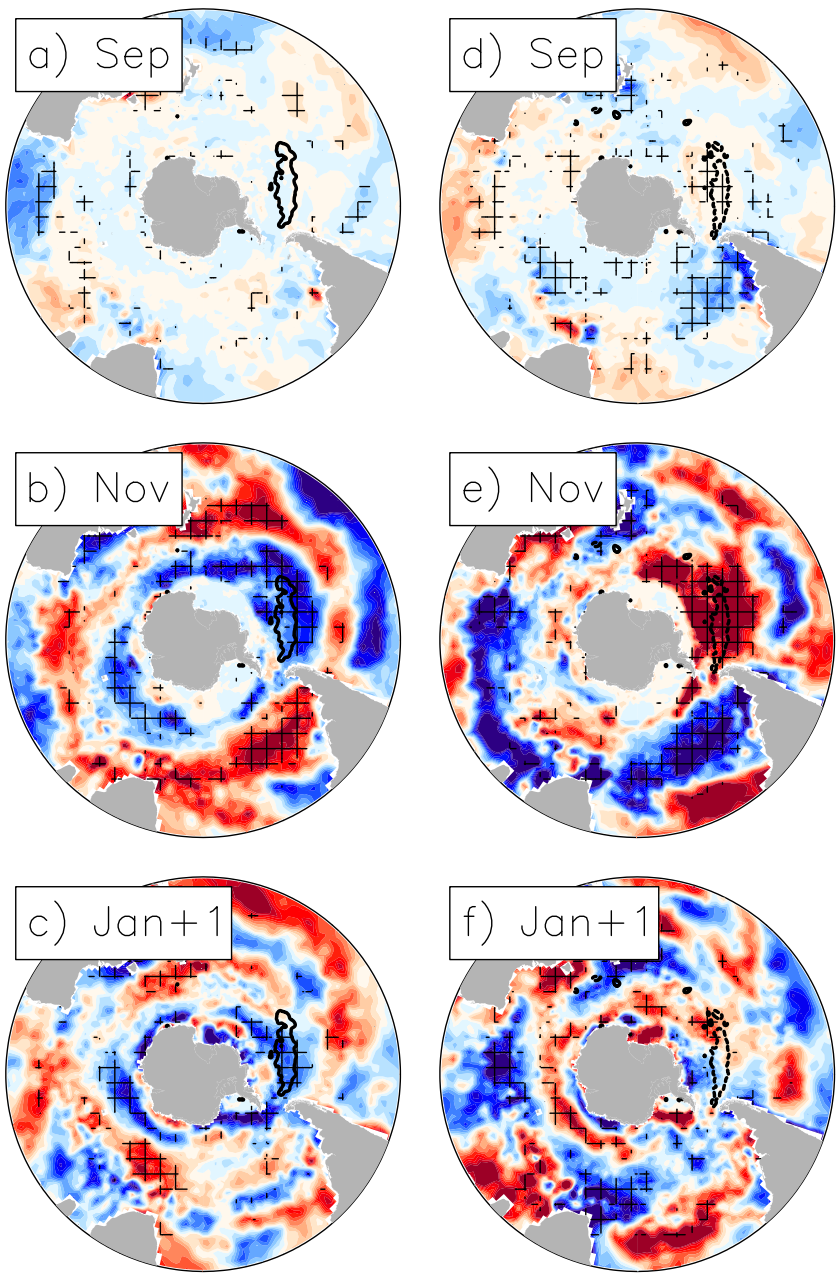

$\mathrm{SAM}^{-}$
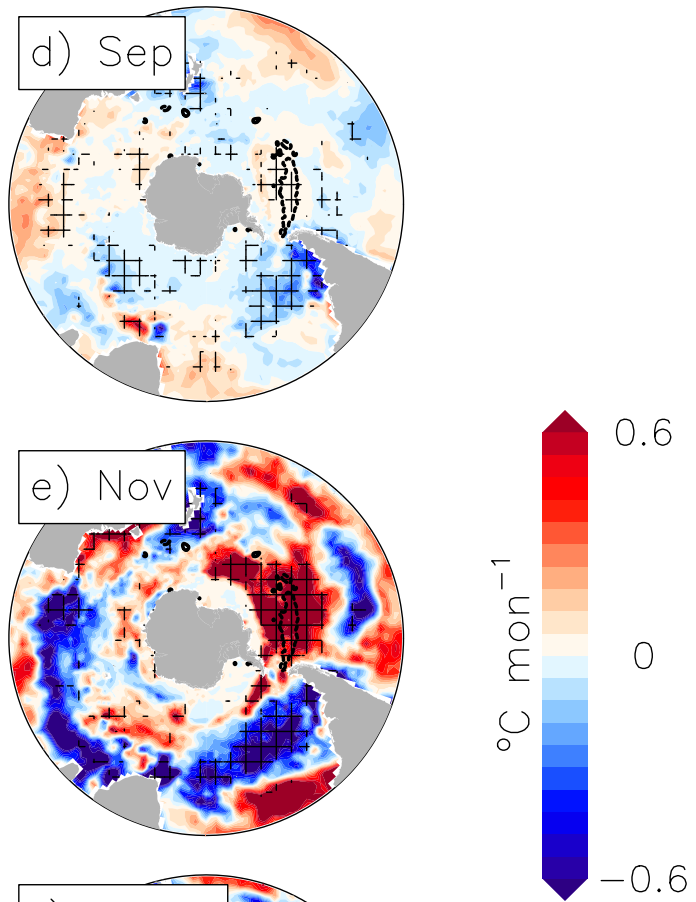

FIG. 9. Composite net air-sea heat flux contribution to the potential temperature tendency anomalies $\left({ }^{\circ} \mathrm{C}_{\text {month }}^{-1}\right.$ ) south of $20^{\circ} \mathrm{S}$ for the (a)-(c) $\mathrm{SAM}^{+}$and (d)-(f) $\mathrm{SAM}^{-}$years from September of the initial SAM ${ }^{+/-}$anomaly to the following January. Stippling denotes regions where the significance level of the anomalies is $>90 \%$ based on a Monte Carlo test from 1000 samples. The "+1" indicates months occurring during the year following the anomalous $\mathrm{SAM}^{+/-}$austral spring.

by salinity is relatively small. It is evident that an anomalous increase (decrease) of mixed layer potential temperature follows the $\mathrm{SAM}^{+}\left(\mathrm{SAM}^{-}\right)$peak anomalies. As will be shown below, these mixed layer anomalies persist and help to account for the largest MLD variations that occur in the following May.

The contributions of net air-sea heat fluxes and the Ekman heat transport to the potential temperature tendency are also evaluated for the southeast Pacific sector (Figs. 12c,g). Consistent with previous studies (e.g., Sallée et al. 2010; Hogg 2010), our results presented in Figs. 9 and 10 show that net air-sea heat fluxes play the major role in the southeast Pacific. As discussed in section 5, Ekman heat transport is of secondary importance in this sector. We interpret the residual (light yellow shading in Figs. 12c and 12g) to represent other processes including non-Ekman advection, eddy mixing, diffusion, and entrainment. The calculation of these terms and closure of the resulting heat budget is difficult unless evaluated online during the model integration (e.g., Holmes et al. 2019). This residual can be interpreted as a buffer of the mixed layer potential temperature changes induced by the net air-sea heat flux, and to a lesser effect, Ekman heat flux. The time series of the terms in (1), shown in Figs. 12d and 12h, reveals that the anomalous ocean latent heat fluxes are roughly 
SAM $^{+}$
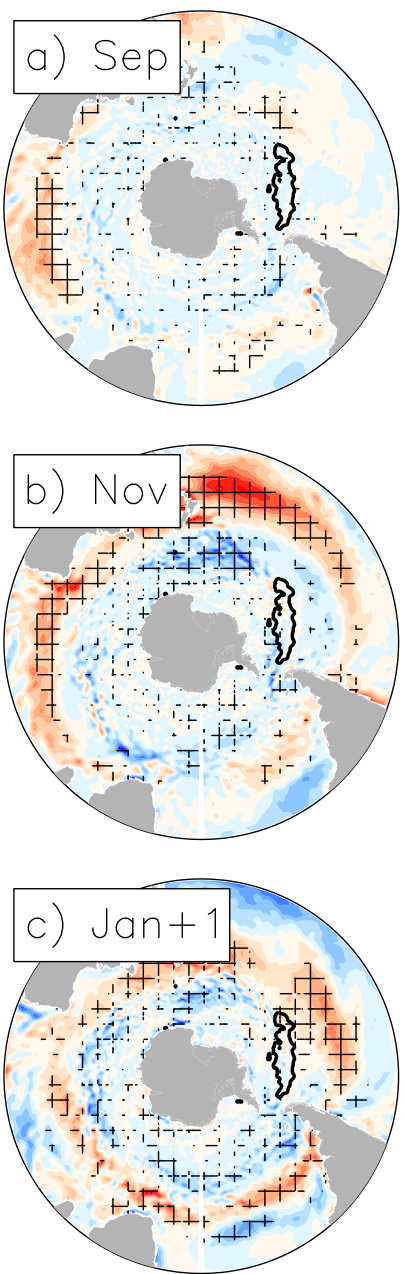

$\mathrm{SAM}^{-}$
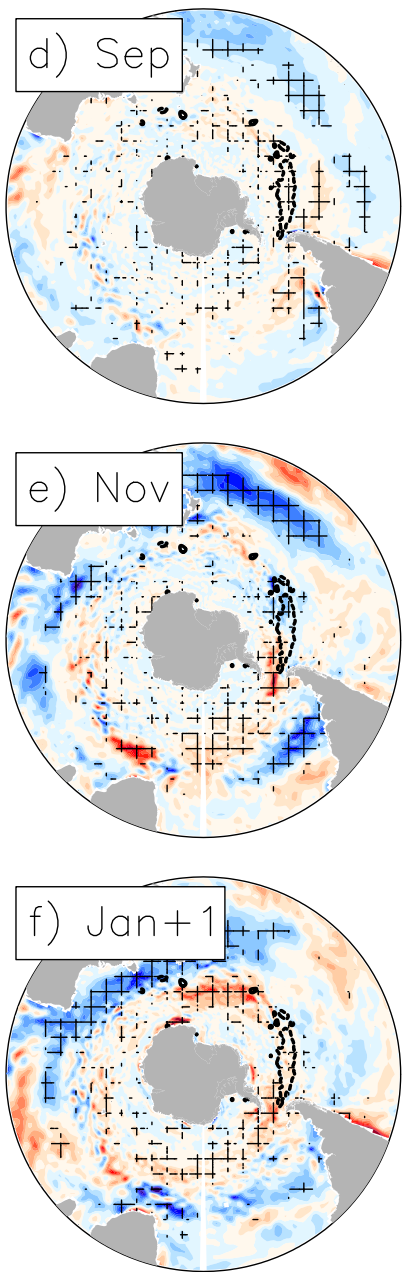

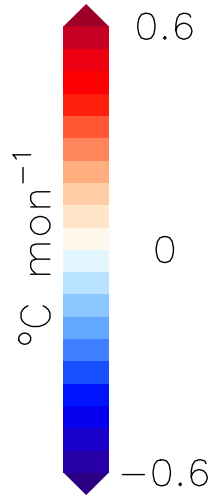

FIG. 10. Composite Ekman heat transport contribution to the potential temperature tendency anomalies $\left({ }^{\circ} \mathrm{C}\right.$ month ${ }^{-1}$ ) south of $20^{\circ} \mathrm{S}$ for the (a)-(c) $\mathrm{SAM}^{+}$and (d)-(f) $\mathrm{SAM}^{-}$years from September of the initial SAM ${ }^{+/-}$anomaly to the following January. Stippling denotes regions where the significance level of the anomalies is $>90 \%$ based on a Monte Carlo test from 1000 samples. The " +1 " indicates months occurring during the year following the anomalous $\mathrm{SAM}^{+/-}$austral spring.

proportional to the magnitude of the anomalous MLD relative to its absolute depth. This indicates that the anomalous ocean latent heat release in the late springtime plays the major role for generating the unusually strong (weak) cooling during $\mathrm{SAM}^{+}\left(\mathrm{SAM}^{-}\right)$years. It is of interest to diagnose the ocean heat content (OHC) anomalies associated with these MLD variations that respond to the SAM. Calculating these anomalies relative to the mean heat content of the ocean yields two peak OHC anomaly values: $2.88 \times 10^{21} \mathrm{~J}$ of extra ocean heat in November and $3.32 \times 10^{21} \mathrm{~J}$ in the following May during $\mathrm{SAM}^{+}$, and $-2.59 \times 10^{21} \mathrm{~J}$ in November and $-2.46 \times 10^{21} \mathrm{~J}$ in the following May for $\mathrm{SAM}^{-}$.
This translates to substantial ocean heat content variations depending on which phase of the SAM is occurring.

\section{b. Ocean interior variations}

The MLD is a direct indicator of ocean vertical stratification. Therefore, to better understand the ocean interior response to the SAM, we examine variations of vertical stratification averaged within the southeast Pacific sector. The stratification variations are measured using buoyancy frequency $N^{2}$ anomalies by taking the vertical derivative of the buoyancy $b$ anomalies, expressed as 

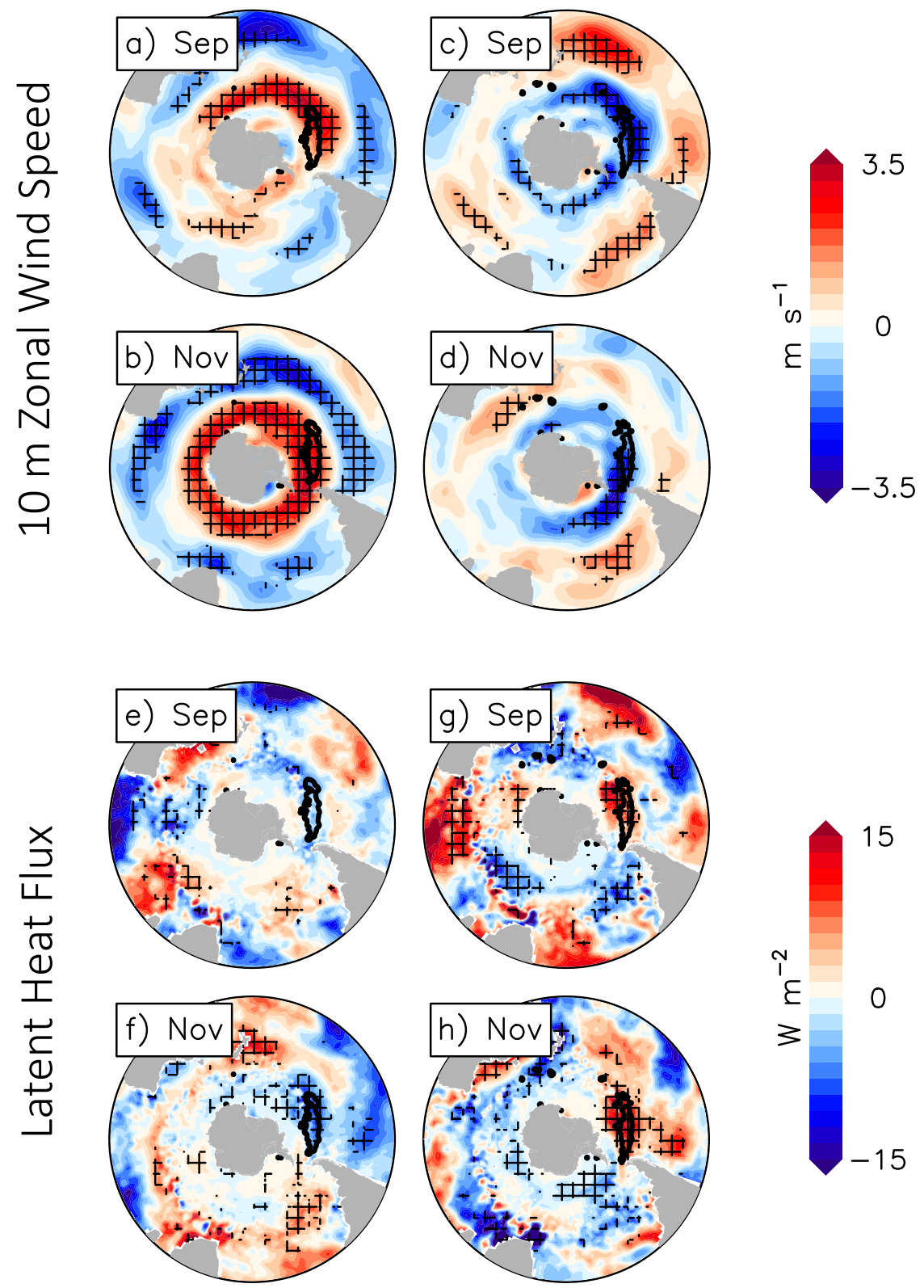

FIG. 11. The (a)-(d) 10-m zonal wind speed anomalies (color; $\mathrm{m} \mathrm{s}^{-1}$ ) and (e)-(h) sea surface latent heat flux anomalies (color; $\mathrm{W} \mathrm{m}^{-2}$ ) in the Southern Hemisphere in September and November for the $\mathrm{SAM}^{+}$and $\mathrm{SAM}^{-}$composites, respectively. Stippling denotes regions where the significance level of the anomalies is $>90 \%$ based on a Monte Carlo test from 1000 samples. The black line indicates the key southeast Pacific sector, defined as the May MLD anomalies at $\pm 30 \mathrm{~m}$.

$$
\Delta N^{2}=\frac{\partial \Delta b}{\partial z}=-\frac{g}{\sigma_{\text {ref }}} \frac{\partial \Delta \sigma}{\partial z}
$$

where $\Delta$ denotes anomalies and $g$ is gravity. Figure 13 shows the climatological buoyancy frequency $\left(N^{2}\right.$; top panel) and the difference between the $\mathrm{SAM}^{+}$and $\mathrm{SAM}^{-}$composites (bottom panel) in austral spring (October), summer (January) and fall (May), respectively. In the springtime, the climatological $N^{2}$ is very weak above $\sim 500 \mathrm{~m}$ (Fig. 13a) and a negative $N^{2}$ 

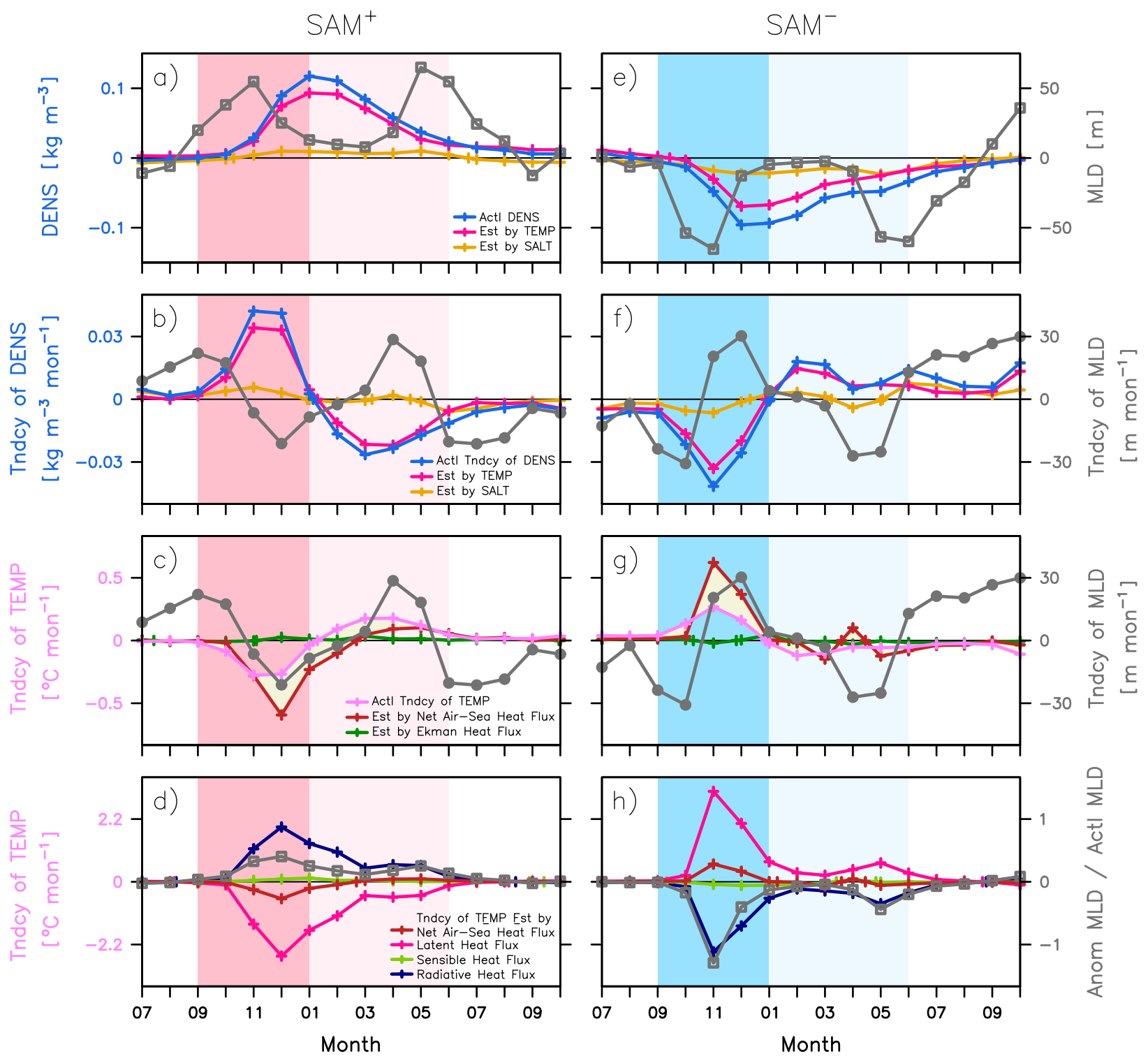

FIG. 12. Time series of properties averaged within the region of deep mixed layer formation in the southeast Pacific Ocean (black contoured region shown in Fig. 6). For the (left) $\mathrm{SAM}^{+}$and (right) $\mathrm{SAM}^{-}$phases, time series of (a),(e) MLD (gray line), potential density (blue line), potential temperature (pink line), and salinity (yellow line) anomalies; (b),(f) tendencies of these anomalies shown with the same colors, respectively; (c),(g) MLD tendency anomalies (gray line), actual potential temperature tendency anomalies (pink line), and the contributions from the net air-sea heat flux (brown line) and Ekman heat flux (green line); and (d),(h) actual potential temperature tendency anomalies (pink line) and the contribution from net air-sea heat flux (brown line) with the components of latent heat flux (dark pink line), sensible heat flux (yellow green line), and radiative heat flux (dark blue line), respectively. These time series are based on a southeast Pacific sector average. Dark pink (left panels) and dark blue (right panels) shading indicates the SAM peak period. Light pink (left panels) and light blue (right panels) shading shows the period of anomalous MLD development in the year following the SAM. In (c) and (g), the light yellow shading denotes a difference between the actual potential temperature tendency anomalies and the contributions from the net air-sea heat flux and Ekman heat flux, which can be interpreted as a residual due to other processes (e.g., non-Ekman advection, eddy mixing, diffusion, and entrainment).

anomaly appears, caused by colder SSTs. During summer, because of the increased radiative heating at the ocean surface, strong restratification occurs in the upper ocean above $\sim 100 \mathrm{~m}$ (Fig. 13b). As a result, the actual MLD becomes shallow, hence MLD anomalies are also very small. However, negative $N^{2}$ anomalies persist above $\sim 85 \mathrm{~m}$, embedded in the summer pycnocline, and also below the summer mixed layer, between 100- and 500-m depth (Fig. 13e). In the fall, the climatological $N^{2}$ starts to weaken again due to upper-ocean cooling 

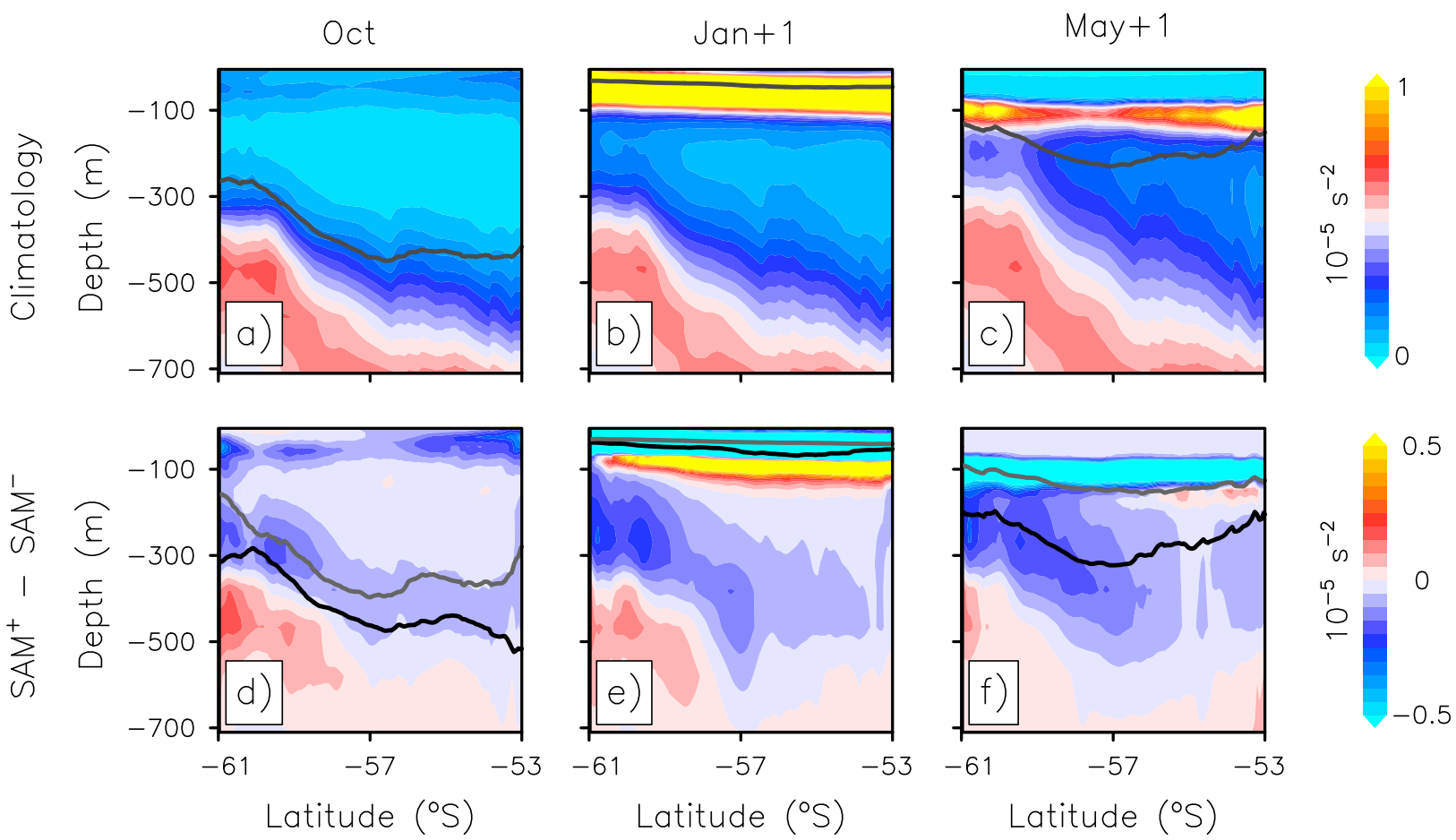

FIG. 13. Vertical cross sections of (a)-(c) climatological buoyancy frequency $N^{2}$ (color; $\mathrm{s}^{-2}$ ) and (d)-(f) the buoyancy frequency difference $\Delta N^{2}$ (color; ${ }^{-2}$ ) between SAM ${ }^{+}$and SAM ${ }^{-}$in October, as well as the following January and May, respectively. In (a)-(c), the dark gray line indicates the climatological MLD. In (d)-(f), black and light gray lines indicate the actual MLDs for the SAM ${ }^{+}$and SAM ${ }^{-}$ composites, respectively. The " +1 " indicates months occurring during the year following the anomalous SAM ${ }^{+/-}$austral spring.

(Fig. 13c). With this cooling, the negative $N^{2}$ anomalies, a legacy of the previous spring cooling caused by strong $\mathrm{SAM}^{+}$winds, appear to spread to depths of $\sim 100-500 \mathrm{~m}$ (Fig. 13f), even though there are no significant atmospheric SAM anomalies during the fall. This anomalously weak ocean interior stratification further promotes deep MLD anomalies in the fall. Therefore, we interpret the May MLD anomaly as an expression of a reemergence of ocean stratification anomalies that were first instigated by the springtime SAM conditions of the previous year. This reemergence mechanism is reminiscent of the North Pacific SST reemergence mechanism described by Alexander et al. (2000).

\section{Conclusions and summary}

We examined the relationship between the most dominant mode of $\mathrm{SH}$ atmospheric variability, known as the SAM, and Southern Ocean MLD using a $0.1^{\circ}$ global ocean model. The SLP evolution shows that the canonical annular SAM structure is most pronounced during austral springtime from September to November. In response to the SAM, however, the MLD variations manifest as zonally asymmetric features several months later. In particular, the greatest MLD anomalies occur in the southeast
Pacific sector in May. The mechanisms regulating this seasonal-to-interannual SAM-MLD relationship were the focus of the analyses presented in this paper.

In response to the $\mathrm{SAM}^{+}$anomalous winds, there is anomalously large ocean latent heat loss in the late spring; this enhanced heat loss is consistent with a SAMrelated poleward intensification of the westerly winds. These latent heat flux anomalies dominate the net airsea heat flux anomalies, which act to promote colder SSTs and weakened ocean interior stratification in the springtime. The anomalously weakened stratification persists in the upper ocean above $\sim 500 \mathrm{~m}$ during the following summer and fall, even though there are no longer any significant atmospheric SAM anomalies. As such, the weak stratification in the interior can be seen as a legacy from the preceding springtime, when SAM anomalies were at their peak. The details of this reemergence mechanism of the MLD anomalies are summarized schematically in Fig. 14.

The southeast Pacific sector that we focused on in this study is a critical location for the SAMW formation (McCartney 1977; Holte and Talley 2009; Sloyan et al. 2010; Cerovečki et al. 2013; Jones et al. 2016), as well as the uptake of heat (Russell et al. 2006; Dong et al. 2008; Roemmich et al. 2015) and carbon (Sarmiento et al. 

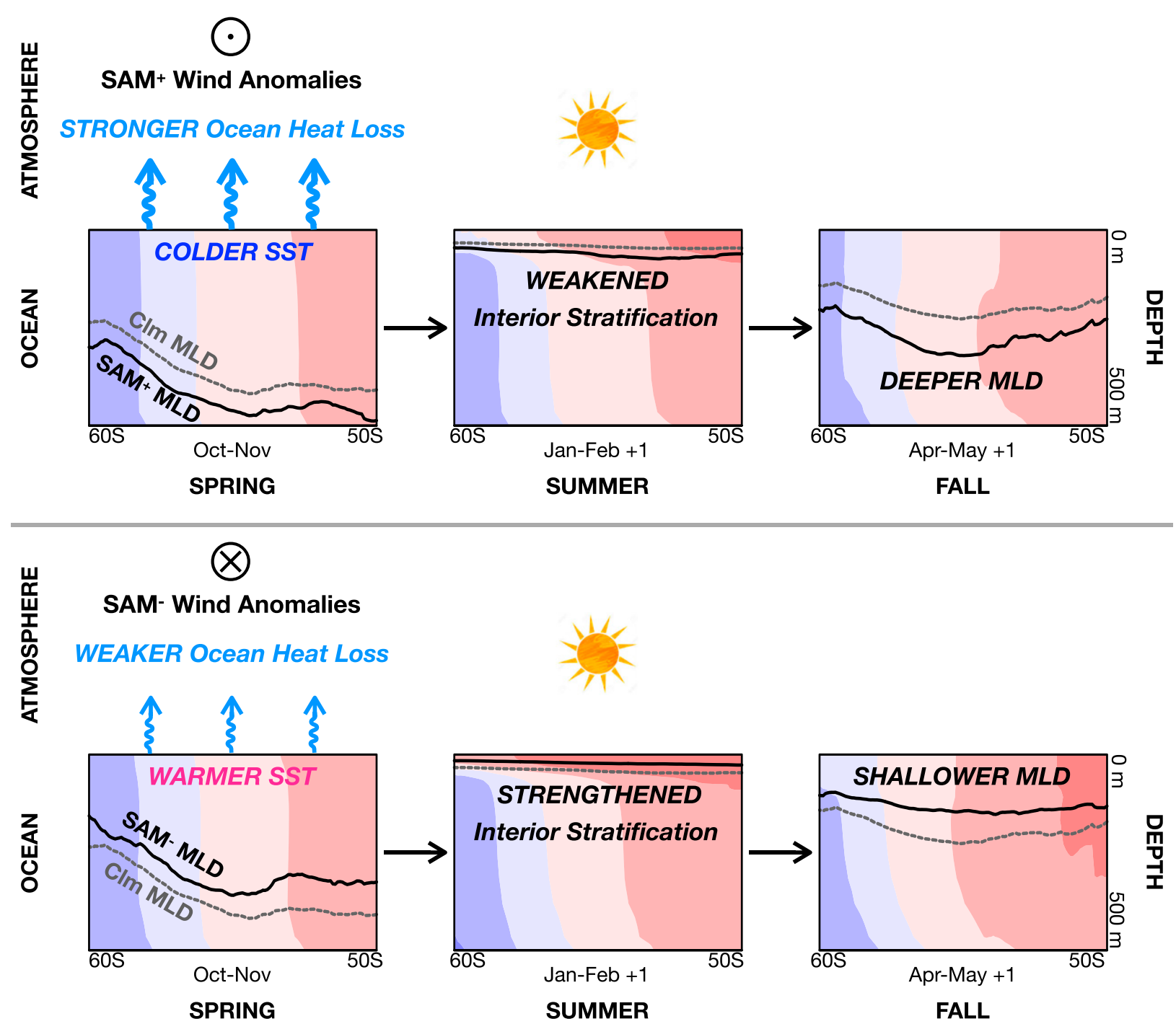

FIG. 14. Schematic diagram of the southeast Pacific variations including the MLD, 10-m zonal wind speed, net air-sea heat flux, SST, ocean potential temperature (color shading), and ocean interior stratification, in response to the (top) SAM ${ }^{+}$and (bottom) SAM ${ }^{-}$phases. The " +1 " indicates months occurring during the year following the anomalous $\mathrm{SAM}^{+/-}$austral spring. In the springtime of the peak $\mathrm{SAM}^{+}\left(\mathrm{SAM}^{-}\right)$anomalies, for the atmosphere, there is stronger (weaker) ocean heat loss primarily contributed by the latent heat flux, consistent with the $\mathrm{SAM}^{+}\left(\mathrm{SAM}^{-}\right)$wind anomalies; for the ocean, there are colder (warmer) SST anomalies and weakened (strengthened) interior stratification. In the summer and fall, even when there are no atmospheric SAM anomalies, the anomalous ocean stratification is a legacy from the previous springtime.

2004; Sabine et al. 2004; Lenton and Matear 2007; Sallée et al. 2012). Our results may thus have implications for understanding variability in ocean ventilation, water mass transformation, and air-sea exchanges of heat and carbon in this region. It is worth noting that the aforementioned reemergence mechanism is mostly evident over the southeast Pacific sector. In the IndianAustralian sector, the mixed layer property anomalies have the opposite sign (Figs. 6-8). This opposing mixed layer tendency suggests that the ocean heat uptake anomalies in the southeast Pacific sector are likely compensated at least partly by those in the IndianAustralian sector.

In addition, previous studies have suggested that it is difficult to separate the influence of the SAM from that of ENSO, particularly in relation to the spatial distribution of sea surface temperature in the Southern Ocean (e.g., Ciasto and Thompson 2008; Vivier et al. 2010; Ciasto and England 2011). Over the analyzed model period of 1994-2007, the SAM-ENSO correlation has been found in previous studies to be stronger than at other time periods (Yu et al. 2015). The SAM-MLD 
relationship identified in this study could thus also be modulated by ENSO. Future work should aim to investigate this possibility using simulations and reanalysis datasets that cover multidecadal time scales.

Acknowledgments. We thank Lynne Talley for helpful discussions about the relationship between the SAM and mode water formation in the Southern Ocean. QL and SL are supported by the National Science Foundation under Grant AGS-1455577. MHE is supported by the Australian Research Council (ARC), including the ARC Centre of Excellence for Climate Extremes, and the Centre for Southern Hemisphere Oceans Research (CSHOR). JLM was supported by DOE U.S. Office of Science Grant DE-SC0014440 for this study. High-performance computing resource Grant TG-OCE110013 (JLM) was used to run the POP simulation at NSF's Extreme Science and Engineering Discovery Environment (XSEDE), while OCE-0850463 supported Elena Yuleva (UCSD) and JLM to carry out the simulation. The POP output is available from XSEDE.

\section{REFERENCES}

Alexander, M. A., J. D. Scott, and C. Deser, 2000: Processes that influence sea surface temperature and ocean mixed layer depth variability in a coupled model. J. Geophys. Res., 105, 16 823-16842, https://doi.org/10.1029/2000JC900074.

Arblaster, J. M., and G. A. Meehl, 2006: Contributions of external forcings to southern annular mode trends. J. Climate, 19, 28962905, https://doi.org/10.1175/JCLI3774.1.

Ayers, J. M., and P. G. Strutton, 2013: Nutrient variability in Subantarctic Mode Waters forced by the southern annular mode and ENSO. Geophys. Res. Lett., 40, 3419-3423, https:// doi.org/10.1002/grl.50638.

Byrne, N. J., T. G. Shepherd, T. Woollings, and R. A. Plumb, 2016: Annular modes and apparent eddy feedbacks in the Southern Hemisphere. Geophys. Res. Lett., 43, 3897-3902, https:// doi.org/10.1002/2016GL068851.

Cai, W., and P. G. Baines, 2001: Forcing of the Antarctic circumpolar wave by El Niño-Southern Oscillation teleconnections. J. Geophys. Res., 106, 9019-9038, https://doi.org/10.1029/2000JC000590.

— lation in IPCC AR4 models over 1950-99: Ozone depletion versus greenhouse forcing. J. Climate, 20, 681-693, https:// doi.org/10.1175/JCLI4028.1.

Cerovečki, I., L. D. Talley, M. R. Mazloff, and G. Maze, 2013: Subantarctic Mode Water formation, destruction, and export in the eddy-permitting Southern Ocean State Estimate. J. Phys. Oceanogr., 43, 1485-1511, https://doi.org/10.1175/ JPO-D-12-0121.1.

Chen, R., J. L. McClean, S. T. Gille, and A. Griesel, 2014: Isopycnal eddy diffusivities and critical layers in the Kuroshio Extension from an eddying ocean model. J. Phys. Oceanogr., 44, 21912211, https://doi.org/10.1175/JPO-D-13-0258.1.

Ciasto, L. M., and D. W. J. Thompson, 2008: Observations of largescale ocean-atmosphere interaction in the Southern Hemi- sphere. J. Climate, 21, 1244-1259, https://doi.org/10.1175/ 2007JCLI1809.1.

-, and M. H. England, 2011: Observed ENSO teleconnections to Southern Ocean SST anomalies diagnosed from a surface mixed layer heat budget. Geophys. Res. Lett., 38, L09701, https://doi.org/10.1029/2011GL046895.

de Boyer Montégut, C., G. Madec, A. S. Fischer, A. Lazar, and D. Iudicone, 2004: Mixed layer depth over the global ocean: An examination of profile data and a profile-based climatology. J. Geophys. Res., 109, C12003, https://doi.org/10.1029/ 2004JC002378.

Delman, A. S., J. L. McClean, J. Sprintall, L. D. Talley, E. Yulaeva, and S. R. Jayne, 2015: Effects of eddy vorticity forcing on the mean state of the Kuroshio Extension. J. Phys. Oceanogr., 45, 1356-1375, https://doi.org/10.1175/JPO-D-13-0259.1.

Dong, S., S. T. Gille, and J. Sprintall, 2007: An assessment of the Southern Ocean mixed layer heat budget. J. Climate, 20, 44254442, https://doi.org/10.1175/JCLI4259.1.

_, J. Sprintall, S. T. Gille, and L. Talley, 2008: Southern Ocean mixed-layer depth from Argo float profiles. J. Geophys. Res., 113, C06013, https://doi.org/10.1029/2006JC004051.

Downes, S. M., A. S. Budnick, J. L. Sarmiento, and R. Farneti, 2011: Impacts of wind stress on the Antarctic Circumpolar Current fronts and associated subduction. Geophys. Res. Lett., 38, L11605, https://doi.org/10.1029/2011GL047668.

du Plessis, M., S. Swart, I. J. Ansorge, A. Mahadevan, and A. F. Thompson, 2019: Southern Ocean seasonal restratification delayed by submesoscale wind-front interactions. J. Phys. Oceanogr., 49, 1035-1053, https://doi.org/10.1175/JPO-D-18-0136.1.

Fogt, R. L., J. M. Jones, and J. Renwick, 2012: Seasonal zonal asymmetries in the southern annular mode and their impact on regional temperature anomalies. J. Climate, 25, 6253-6270, https://doi.org/10.1175/JCLI-D-11-00474.1.

Frölicher, T. L., J. L. Sarmiento, D. J. Paynter, J. P. Dunne, J. P. Krasting, and M. Winton, 2015: Dominance of the Southern Ocean in anthropogenic carbon and heat uptake in CMIP5 models. J. Climate, 28, 862-886, https://doi.org/10.1175/ JCLID-14-00117.1.

Fyfe, J. C., O. A. Saenko, K. Zickfeld, M. Eby, and A. J. Weaver, 2007: The role of poleward-intensifying winds on Southern Ocean warming. J. Climate, 20, 5391-5400, https://doi.org/ 10.1175/2007JCLI1764.1.

Gillett, N. P., and D. W. J. Thompson, 2003: Simulation of recent Southern Hemisphere climate change. Science, 302, 273-275, https://doi.org/10.1126/science.1087440.

_ J. C. Fyfe, and D. E. Parker, 2013: Attribution of observed sea level pressure trends to greenhouse gas, aerosol, and ozone changes. Geophys. Res. Lett., 40, 2302-2306, https://doi.org/ 10.1002/grl.50500.

Gong, D., and S. Wang, 1999: Definition of Antarctic Oscillation index. Geophys. Res. Lett., 26, 459-462, https://doi.org/10.1029/ 1999GL900003.

Gong, T., S. B. Feldstein, and D. Luo, 2010: The impact of ENSO on wave breaking and southern annular mode events. J. Atmos. Sci., 67, 2854-2870, https://doi.org/10.1175/ 2010JAS3311.1.

Hall, A., and M. Visbeck, 2002: Synchronous variability in the Southern Hemisphere atmosphere, sea ice, and ocean resulting from the annular mode. J. Climate, 15, 3043-3057, https://doi.org/10.1175/1520-0442(2002)015<3043:SVITSH > 2.0.CO;2. 
Hartmann, D. L., and F. Lo, 1998: Wave-driven zonal flow vacillation in the Southern Hemisphere. J. Atmos. Sci., 55, 1303-1315, https:// doi.org/10.1175/1520-0469(1998)055<1303:WDZFVI>2.0.CO;2.

Hogg, A. M., 2010: An Antarctic Circumpolar Current driven by surface buoyancy forcing. Geophys. Res. Lett., 37, L23601, https://doi.org/10.1029/2010GL044777.

Holmes, R. M., J. D. Zika, and M. H. England, 2019: Diathermal heat transport in a global ocean model. J. Phys. Oceanogr., 49, 141-161, https://doi.org/10.1175/JPO-D-18-0098.1.

Holte, J., and L. Talley, 2009: A new algorithm for finding mixed layer depths with applications to Argo data and Subantarctic Mode Water formation. J. Atmos. Oceanic Technol., 26, 1920 1939, https://doi.org/10.1175/2009JTECHO543.1.

, - - T. K. Chereskin, and B. M. Sloyan, 2012: The role of air-sea fluxes in Subantarctic Mode Water formation. J. Geophys. Res., 117, C03040, https://doi.org/10.1029/ 2011JC007798.

— L. D. Talley, J. Gilson, and D. Roemmich, 2017: An Argo mixed layer climatology and database. Geophys. Res. Lett., 44, 5618-5626, https://doi.org/10.1002/2017GL073426.

Jones, D. C., A. J. S. Meijers, E. Shuckburgh, J. B. Sallée, P. Haynes, E. K. McAufield, and M. R. Mazloff, 2016: How does Subantarctic Mode Water ventilate the Southern Hemisphere subtropics? J. Geophys. Res. Oceans, 121, 65586582, https://doi.org/10.1002/2016JC011680.

Kidson, J. W., 1999: Principal modes of Southern Hemisphere lowfrequency variability obtained from NCEP-NCAR reanalyses. J. Climate, 12, 2808-2830, https://doi.org/10.1175/1520-0442(1999) 012<2808:PMOSHL $>2.0$. CO; 2 .

Kushner, P. J., I. M. Held, and T. L. Delworth, 2001: Southern Hemisphere atmospheric circulation response to global warming. J. Climate, 14, 2238-2249, https://doi.org/10.1175/ 1520-0442(2001)014<0001:SHACRT $>2.0 . C O ; 2$.

Large, W. G., and S. G. Yeager, 2009: The global climatology of an interannually varying air-sea flux data set. Climate Dyn., 33, 341-364, https://doi.org/10.1007/s00382-008-0441-3.

- G. Danabasoglu, S. C. Doney, and J. C. McWilliams, 1997: Sensitivity to surface forcing and boundary layer mixing in a global ocean model: Annual-mean climatology. J. Phys. Oceanogr., 27, 2418-2447, https://doi.org/10.1175/1520-0485(1997) 027<2418:STSFAB $>2.0 . \mathrm{CO} ; 2$.

Lee, M. M., A. J. G. Nurser, I. Stevens, and J. B. Sallée, 2011: Subduction over the southern Indian Ocean in a highresolution atmosphere-ocean coupled model. J. Climate, 24, 3830-3849, https://doi.org/10.1175/2011JCLI3888.1.

Lenton, A., and R. J. Matear, 2007: Role of the southern annular mode (SAM) in Southern Ocean $\mathrm{CO}_{2}$ uptake. Global Biogeochem. Cycles, 21, GB2016, https://doi.org/10.1029/ $2006 \mathrm{~GB} 002714$.

L'Heureux, M. L., and D. W. Thompson, 2006: Observed relationships between the El Niño-Southern Oscillation and the extratropical zonal-mean circulation. J. Climate, 19, 276-287, https://doi.org/10.1175/JCLI3617.1.

Li, Q., and S. Lee, 2017: A mechanism of mixed-layer formation in the Indo-western Pacific Southern Ocean: Preconditioning by an eddy-driven jet-scale overturning circulation. J. Phys. Oceanogr., 47, 2755-2772, https://doi.org/10.1175/JPO-D-170006.1.

Lim, E., H. H. Hendon, and H. Rashid, 2013: Seasonal predictability of the southern annular mode due to its association with ENSO. J. Climate, 26, 8037-8054, https://doi.org/10.1175/ JCLI-D-13-00006.1.
Limpasuvan, V., and D. L. Hartmann, 1999: Eddies and the annular modes of climate variability. Geophys. Res. Lett., 26, 31333136, https://doi.org/10.1029/1999GL010478.

Lorenz, D. J., and D. L. Hartmann, 2001: Eddy-zonal flow feedback in the Southern Hemisphere. J. Atmos. Sci., 58, 3312-3327, https:// doi.org/10.1175/1520-0469(2001)058<3312:EZFFIT>2.0.CO;2.

Maltrud, M. E., F. Bryan, and S. Peacock, 2010: Boundary impulse response functions in a century-long eddying global ocean simulation. Environ. Fluid Mech., 10, 275-295, https://doi.org/ 10.1007/s10652-009-9154-3.

Marshall, G. J., 2003: Trends in the southern annular mode from observations and reanalyses. J. Climate, 16, 4134 4143, https://doi.org/10.1175/1520-0442(2003)016<4134: TITSAM $>2.0 . \mathrm{CO} ; 2$.

McCartney, M. S., 1977: Subantarctic mode water. A Voyage of Discovery, M. Angel, Ed., Elsevier, 103-119.

McDougall, T. J., D. R. Jackett, D. G. Wright, and R. Feistel, 2003: Accurate and computationally efficient algorithms for potential temperature and density of seawater. J. Atmos. Oceanic Technol., 20, 730-741, https://doi.org/10.1175/1520-0426(2003) 20<730:AACEAF $>2.0 . \mathrm{CO} ; 2$.

Purich, A., and Coauthors, 2016: Tropical Pacific SST drivers of recent Antarctic sea ice trends. J. Climate, 29, 8931-8948, https://doi.org/10.1175/JCLI-D-16-0440.1.

Rashid, H. A., and I. Simmonds, 2005: Southern Hemisphere annular mode variability and the role of optimal nonmodal growth. J. Atmos. Sci., 62, 1947-1961, https://doi.org/10.1175/ JAS3444.1.

Rintoul, S. R., and M. H. England, 2002: Ekman transport dominates local air-sea fluxes in driving variability of Subantarctic Mode Water. J. Phys. Oceanogr., 32, 1308-1321, https://doi.org/ 10.1175/1520-0485(2002)032<1308:ETDLAS > 2.0.CO;2.

Roemmich, D., J. Church, J. Gilson, D. Monselesan, P. Sutton, and S. Wijffels, 2015: Unabated planetary warming and its ocean structure since 2006. Nat. Climate Change, 5, 240-245, https:// doi.org/10.1038/nclimate2513.

Rudnick, D. L., and R. Ferrari, 1999: Compensation of horizontal temperature and salinity gradients in the ocean mixed layer. Science, 283, 526-529, https://doi.org/10.1126/science.283.5401.526.

Russell, J. L., K. W. Dixon, A. Gnanadesikan, R. J. Stouffer, and J. R. Toggweiler, 2006: The Southern Hemisphere westerlies in a warming world: Propping open the door to the deep ocean. J. Climate, 19, 6382-6390, https://doi.org/10.1175/ JCLI3984.1.

Sabine, C. L., and Coauthors, 2004: The oceanic sink for anthropogenic $\mathrm{CO}_{2}$. Science, 305, 367-371, https://doi.org/10.1126/ science.1097403.

Sallée, J. B., N. Wienders, K. Speer, and R. Morrow, 2006: Formation of subantarctic mode water in the southeastern Indian Ocean. Ocean Dyn., 56, 525-542, https://doi.org/10.1007/ s10236-005-0054-x

- K. Speer, and S. Rintoul, 2010: Zonally asymmetric response of the Southern Ocean mixed-layer depth to the southern annular mode. Nat. Geosci., 3, 273-279, https://doi.org/ 10.1038/ngeo812.

— R. Matear, S. R. Rintoul, and A. Lenton, 2012: Localised subduction of anthropogenic carbon dioxide in the Southern Hemisphere oceans. Nat. Geosci., 5, 579-584, https://doi.org/ 10.1038/ngeo1523.

Sarmiento, J. L., N. Gruber, M. A. Brzezinski, and J. P. Dunne, 2004: High-latitude controls of thermocline nutrients and low latitude biological productivity. Nature, 427, 56-60, https:// doi.org/10.1038/nature02127. 
Schiller, A., and K. R. Ridgway, 2013: Seasonal mixed-layer dynamics in an eddy-resolving ocean circulation model. J. Geophys. Res. Oceans, 118, 3387-3405, https://doi.org/10.1002/jgrc.20250.

Screen, J. A., N. P. Gillett, D. P. Stevens, G. J. Marshall, and H. K. Roscoe, 2009: The role of eddies in the Southern Ocean temperature response to the southern annular mode. J. Climate, 22, 806-818, https://doi.org/10.1175/2008JCLI2416.1.

Seager, R., N. Harnik, Y. Kushnir, W. Robinson, and J. Miller, 2003: Mechanisms of hemispherically symmetric climate variability. J. Climate, 16, 2960-2978, https://doi.org/10.1175/ 1520-0442(2003)016<2960:MOHSCV > 2.0.CO;2.

Sen Gupta, A., and M. H. England, 2006: Coupled oceanatmosphere-ice response to variations in the southern annular mode. J. Climate, 19, 4457-4486, https://doi.org/10.1175/ JCLI3843.1.

Simpson, I. R., P. Hitchcock, T. G. Shepherd, and J. F. Scinocca, 2011: Stratospheric variability and tropospheric annular-mode timescales. Geophys. Res. Lett., 38, L20806, https://doi.org/ 10.1029/2011GL049304.

Sloyan, B. M., L. D. Talley, T. K. Chereskin, R. Fine, and J. Holte, 2010: Antarctic Intermediate Water and Subantarctic Mode Water formation in the southeast Pacific: The role of turbulent mixing. J. Phys. Oceanogr., 40, 1558-1574, https://doi.org/ 10.1175/2010JPO4114.1.

Smith, R. D., J. K. Dukowicz, and R. C. Malone, 1992: Parallel ocean general circulation modeling. Physica D, 60, 38-61, https://doi.org/10.1016/0167-2789(92)90225-C.
Thompson, D. W. J., and J. M. Wallace, 2000: Annular modes in the extratropical circulation. Part I: Month-to-month variability. J. Climate, 13, 1000-1016, https://doi.org/10.1175/15200442(2000)013<1000:AMITEC > 2.0.CO;2.

, and S. Solomon, 2002: Interpretation of recent Southern Hemisphere climate change. Science, 296, 895-899, https:// doi.org/10.1126/science.1069270.

Treguier, A. M., J. Le Sommer, J. M. Molines, and B. de Cuevas, 2010: Response of the Southern Ocean to the southern annular mode: Interannual variability and multidecadal trend. J. Phys. Oceanogr., 40, 1659-1668, https://doi.org/10.1175/2010JPO4364.1.

Venegas, S. A., 2003: The Antarctic circumpolar wave: A combination of two signals? J. Climate, 16, 2509-2525, https://doi.org/ 10.1175/1520-0442(2003)016<2509:TACWAC $>2.0$.CO;2.

Vivier, F., D. Iudicone, F. Busdraghi, and Y.-H. Park, 2010: Dynamics of sea-surface temperature anomalies in the Southern Ocean diagnosed from a 2D mixed-layer model. Climate Dyn., 34, 153-184, https://doi.org/10.1007/s00382-009-0724-3.

Williams, R. G., C. Wilson, and C. W. Hughes, 2007: Ocean and atmosphere storm tracks: The role of eddy vorticity forcing. J. Phys. Oceanogr., 37, 2267-2289, https://doi.org/10.1175/ JPO3120.1.

Yu, J., H. Paek, E. S. Saltzman, and T. Lee, 2015: The early 1990s change in ENSO-PSA-SAM relationships and its impact on Southern Hemisphere climate. J. Climate, 28, 9393-9408, https://doi.org/10.1175/JCLI-D-15-0335.1. 